\title{
Introducing DMPA injectable contraceptives to private medical practitioners in urban Gujarat
}

Frontiers in Reproductive Health

Follow this and additional works at: https://knowledgecommons.popcouncil.org/departments_sbsr-rh

Part of the Demography, Population, and Ecology Commons, International Public Health Commons, Maternal and Child Health Commons, and the Women's Health Commons How does access to this work benefit you? Let us know!

\section{Recommended Citation}

Introducing DMPA injectable contraceptives to private medical practitioners in urban Gujarat, FRONTIERS Final Report. Washington, DC: Population Council, 2003. 


\title{
Introducing DMPA Injectable Contraceptives to Private Medical Practitioners in Urban Gujarat
}

\author{
Frontiers in Reproductive Health \\ Population Council \\ New Delhi, India \\ In collaboration with: \\ DKT India \\ EngenderHealth \\ CORT
}

March 2003

This study was funded by the United States Agency for International Development (USAID) under the terms of Cooperative Agreement number HRN-A-00-98-00012-00 and Population Council project number 801313034 454. The opinions expressed herein are those of the authors and do not necessarily reflect the views of USAID. 


\section{SUMMARY}

The national family welfare program in India does not currently include injectable contraceptives in its mix of contraceptive methods that are offered in public sector clinics. Although both types of injectable contraceptives (NetEn and DMPA) are approved for commercial sale by the Drug Controller of India and are available with a doctor's prescription, the Ministry of Health and Family Welfare has not begun routine procurement of either contraceptive method. There has not been a large body of research on the use dynamics of injectable contraceptives in India that could be used to guide policy decisions on the addition of the method. The few studies that have been conducted indicate positive results and hence suggest an important role for the method in the national family planning program.

Pharmacia \& Upjohn conducted a "Post Marketing Surveillance Study on Injection DepoProvera" " that was designed to assess the safety and acceptability of DMPA among a sample of 1,079 women. The large majority of these women $(84.2 \%)$ continued with the method through five doses. Side effects were common, as almost 80 percent of the subjects in this study reported experiencing one or more medical events during the study period, though only three of these cases were considered serious. The conclusion from this 1999 study is that "DMPA $150 \mathrm{mg}$ is a safe and effective contraceptive, and that sufficient pre-treatment counseling on the expected hormonal effects will greatly increase the acceptability of this method of contraception" (PMS Final report, page 2).

The Population Council's Asia and the Near East OR/TA Project conducted an operations research study on the effect of price changes on perceptions and use of DMPA in Uttar Pradesh in association with Parivar Seva Sanstha in 1998. ${ }^{2}$ This study examined patterns of use when three different prices were charged for the DMPA method in the clinics of an affiliate of Marie Stopes International. Although overall continuation with the method was observed to be low, with less than one-fifth (19\%) of the women continuing through four doses, users' perceptions were positive and women who could not tolerate a side effect were able to switch to another, more acceptable method. A wholesale price of Rs. 35 was estimated as the most affordable price for the DMPA in the setting of this study. These two studies are the most recent investigations into the use dynamics of DMPA in India.

Public debate on injectable contraceptives in India is still characterized by strident rhetoric that often polarizes discussions. This has restrained the implementation of a large-scale, national program for injectable contraceptives in India. However, many public, NGO and private sector service delivery systems are suitably matched to the requirements of providing injectable contraceptives, including the ability to ensure choice and service delivery quality. This operations research study was designed to demonstrate the feasibility of providing injectable contraceptives in private medical practices and to contribute to the body of scientific literature on the acceptability of this method in India. DKT India and EngenderHealth formed a partnership with the Population Council's Frontiers in Reproductive Health program to conduct this operations research in Gujarat between July1999 and August 2001.

\footnotetext{
1 "Post Marketing Surveillance Study of Injectable Contraceptive Depo-Provera in Indian Women,” R. P. Soonawala, David Zambrano and F. Tam. Pharmacia \& Upjohn. October 8, 1999. New Delhi, India.

2 "Analysis of Price Change on the Perceptions and Use of DMPA among Clients Using Reproductive Health Services in Uttar Pradesh, India." Leila Caleb-Varkey, John W. Townsend, Sneh Vishwanath and Sudha Tewari. The Population Council. March 27, 1998. New Delhi, India.
} 


\section{Collaborating Agencies}

The DKT social marketing programs in India have been at the forefront of exploring alternative contraceptive options and delivery systems. DKT India is a leader in this field and has a proven record in establishing sustainable marketing systems for oral contraceptives and condoms (among other products) in several states. DKT India first included injectable contraceptives in its program in mid-1996 when NetEn was piloted in a social marketing project in Maharashtra and Gujarat. In 1999, DKT began to introduce DMPA into its programs in Maharashtra and Gujarat.

DKT India contacted approximately 100 private sector providers in Ahmedabad, Baroda and Surat (this number was increased by EngenderHealth in the process of arranging for the professional seminars) about participating in the study. In addition to assisting the study in identifying participating physicians, DKT India provided an uninterrupted source of DMPA injectable contraceptives at a subsidized price of Rs. 40 to their stockists (small, local pharmaceutical providers who are associated with the DKT India program).

A key element of this study was to demonstrate that communication practices and DMPA counseling could be improved in private practice settings. This study also sought to determine whether a standard level of technical knowledge exists among all the providers in the study.

A partnership was formed with EngenderHealth in India to ensure these two aspects of the study and to coordinate the design and implementation of the professional development seminars and IEC material production with DKT India and FRONTIERS. Funds for the EngenderHealth organized activities were provided through the Population Council's Expanding Contraceptive Choice program.

EngenderHealth, working with locally recruited and respected consultants, organized eight one-day training programs that functioned as a type of professional development seminar for the 241 physicians. Of these, 159 physicians agreed to participate in the operations research study at the end of the seminar. EngenderHealth also conducted one-day training sessions for 43 DKT India staff between January and May 2000. These short courses were designed to upgrade the technical knowledge and communication skills related to DMPA and to provide practical guidance to the DKT India sales force on how to interact with physicians to ensure informed choice of DMPA. In addition to the training programs for physicians and DKT India staff, EngenderHealth staff and consultants also conducted follow-up visits between February and June 2000 with all 159 physicians who took part in the seminars.

\section{Study Design}

The study utilized a post-test only, uncontrolled study design that retrospectively investigated the contraceptive practices of all first-time DMPA users in the private practice settings that participated in the DKT India social marketing of contraceptives program in Gujarat. The original proposal called for 100 private sector physicians to be enrolled in the study, but once field operations began this number was expanded to 158 (in order to achieve a larger sample of first-time DMPA users).

Physicians who participated in the study conveyed to all first-time DMPA users a standard informed consent statement (written in Gujarati and Hindi) that described the study's objectives and requested permission to conduct a follow-up interview in seven months (i.e., after receiving 
three doses of DMPA). DMPA clients were considered eligible for the study if they had never used an injectable contraceptive previously (but could have used another contraceptive method), were resident in the nearby vicinity of the physician's practice and had the intention to remain at their present address for approximately 9-12 months. Client enrollment began on April 1, 2000 and continued through September 30, 2001. Representatives of CORT collected the client enrollment cards on a monthly basis throughout the six-month period.

\section{Limitations to the Study}

- Small sample size originally predicted was reduced by approximately 60 percent due to January 2001 earthquake.

- High lost to follow-up rate among clients who remained in the study sample limits the ability to generalize results.

- Client background characteristics are somewhat unique: older, better educated, lower parity and higher previous contraceptive use history than general population.
A subagreement was issued to CORT for the organization and conduction of the client and provider surveys. The study's six-month data collection period began fieldwork operations on November 1, 2000 and continued without interruption until late January 2001. All of the first-time DMPA users who enrolled in the study during April-June 2000 and approximately 75 percent of the 158 providers had been contacted for interviews by that date. On January 26, 2001 a severe earthquake occurred in Gujarat, devastating many areas of the state and substantially damaging large portions of Ahmedabad and Surat, with less physical destruction in Baroda. The earthquake had multiple effects on the client follow-up study, primarily through the profound disruption to daily life even in the study areas that were not directly afflicted with physical destruction. These

overwhelming environmental effects on the study caused the follow-up interview period to be truncated and the elimination of all clients who had been enrolled between July-October 2001. Clients who were enrolled before that time and who were interviewed before the earthquake were kept in the study. The remaining interviews with physicians continued after a pause, as the remainder of these cases were in Baroda and other areas less affected by the earthquake, and the indicators measured in the provider survey were less likely to be disrupted.

\section{Results: Physicians}

Approximately 88 percent of these physicians $(n=139)$ were successfully contacted and completed the interviews during this study. Overall the physician response rate in the study was strong and there is no indication that the missing 12 percent of the original sample in any way substantially biases the results that are presented here.

The sample of physicians was nearly evenly divided by gender with 71 of the respondents being male and 68 female. Almost two-thirds $(60 \%, n=83)$ were OB/GYN specialists and all of the others $(40 \%, \mathrm{n}=56)$ were MBBS, or generalists. Among the OB/GYN specialists 69 percent were female, whereas most $(80 \%)$ of the MBBS physicians were male. The average length of time that physicians in this sample had been providing medical services was quite long (17.4 years). In general the sample is almost evenly divided between physicians who prescribe medicine (51\%) and those who both prescribe and dispense medicine including contraceptive methods such as the IUD, pills and DMPA injections (49\%).

The physicians in this study cannot be characterized as "family planning service providers." They are all for-profit private practice physicians whose clinical practice involves either general primary care services (principally curative services) for the MBBS physicians, or obstetrical care for the OB/GYN specialists. These providers operate out of small clinics, 
usually consisting of a waiting area and a single consultation room without laboratory facilities on site. The results indicate that family planning services are more likely to be provided by the OB/GYN specialists than the MBBS: approximately three out of every four $\mathrm{OB} / \mathrm{GYN}$ specialists $(76 \%)$ reported that they provide a full range of family planning services to their patients, as opposed to fewer than one in every $10(7 \%)$ of the MBBS physicians.

Each of the physicians in the study took part in one or more of the professional seminars organized by EngenderHealth. The three most frequently cited reasons for participating in the seminars and study were 1) a belief that DMPA is a good contraceptive method $(21 \%) ; 2)$ to gain more knowledge about the national family planning program (19\%); and 3) peer pressure to attend due to the seniority of the trainers $(16 \%)$. The majority of the physicians $(63 \%)$ reported that the EngenderHealth seminars were "very useful," principally because of the contraceptive technology update information that was presented by the trainers $(52 \%$ of all physicians cited "latest knowledge" as the principal reason for finding the seminar useful to their medical practice). Approximately twothirds of the 139 physicians (65\%) reported that their clinical practice changed as a result of taking part in the study.

Approximately one-fifth (17\%) of the physicians in this study reported that before taking part in the DKT social marketing program and EngenderHealth seminars they had prescribed or otherwise provided NetEn to one or more of their patients. After taking part in the study the large majority $(81 \%)$ of the physicians interviewed reported having provided, prescribed or counseled one or more patients about DMPA. The average number of patients that the physicians in the study reported who were currently using DMPA injectables was 10 . There is a substantial difference in the mean number of DMPA users by type of provider: MBBS physicians reported a mean of only 5.3 DMPA users while OB/GYN specialists reported a mean of 13.3 DMPA users.

\section{Key Results from Providers' Survey}

- Eighty-eight percent of the 158 private practice physicians were interviewed 8-12 months after they had attended an EngenderHealth training session on DMPA.

- Sixty percent of the physicians in the study are $\mathrm{OB} / \mathrm{GYN}$ specialists and 40 percent are MBBS $(n=139)$

- Average daily caseload: $\mathrm{OB} / \mathrm{GYN}=25$ patients, $\mathrm{MBBS}=48$ patients

- The three most common reasons given for participating in the study and the EngenderHealth seminar: Believe DMPA is a good method (21\%); Gain more knowledge about family planning $(19 \%)$; Peer pressure to attend (16\%).

- About two-thirds of the physicians $(63 \%)$ reported that the EngenderHealth seminars were "very useful."

- Sixty-five percent of the physicians interviewed reported that their clinical practice changed as a result of participating in the study/attending the EngenderHealth seminar.

- Eighty-one percent of the physicians reported either regularly counseling patients about DMPA or providing/prescribing the method.

- Almost all of the physicians (92\%) accurately reported one or more techniques for managing common side effects of DMPA use.

- Thirty-seven percent of the physicians correctly reported that fertility normally returns within six months after discontinuing use of DMPA.

The findings from the survey of physicians' technical knowledge cannot be attributed to the EngenderHealth professional seminar/training program, because the study did not obtain a baseline indicator of the participating physicians' knowledge before the study began, nor did it include a comparison group of physicians who did not participate in the seminars. 
However the findings on the level of physician technical knowledge are indicative of their capacity to provide quality services. About two-thirds of the physicians in the study $(62 \%)$ gave only a single correct answer as to the time a woman can begin using DMPA (e.g., some physicians were unclear about when a woman should begin if she were breastfeeding, had had an abortion or was not between the first and seventh day of menstruation). The large majority of the physicians in the study knew the principal mechanisms of action that DMPA exerts to avoid pregnancy. Physicians' knowledge of the disadvantages and side effects of DMPA are about the same level as their knowledge of the benefits. Approximately threequarters $(75 \%)$ of the physicians in this study gave between one and four disadvantages of the three-month injectable contraceptive method. The large majority (approximately 89\%) of the physicians in the study reported knowing between one and five side effects, most commonly citing amenorrhoea (49\%) and weight gain (35\%).

Almost all of the physicians in the study ( $92 \%$ ) accurately reported one or more techniques for managing bleeding problems caused by DMPA, and about one-quarter (24\%) reported three or more things that they could do to assist women in managing this most commonlycited disadvantage of the contraceptive method. However, important differences did emerge in the number of management techniques that MBBS physicians reported as compared to OB/GYN specialists: approximately one-fifth of the MBBS physicians (18\%) could not suggest a single technique for managing bleeding disorders, whereas only one OB/GYN physician (approximately $1 \%$ of the sample) could not cite a management technique.

When physicians were asked to list what they considered to be major contraindications to DMPA use, the responses indicated a mixed level of understanding about the method specifically and family planning in general. Approximately one-fifth to one-sixth of the physicians in the study (15\% - 20\% range) gave medically correct responses, (e.g., hypertension, breast cancer, diabetes or liver disease). The result that approximately 10 percent of the physicians in the study reported that DMPA was contraindicated for newly married or nulliparous women suggests that a small but important proportion of physicians do not support the use of contraceptives for delaying the first birth.

\section{Results: First-Time DMPA Users}

A total of 352 first-time DMPA clients agreed to take part in the follow-up interview during the three-month enrollment period of April-June 2000. These clients formed the sample for this study. The lost to follow-up rate for the subjects of this study is substantial (48\%). In part this is due to the fact that one-third of the sample (36\%) gave address information that was incorrect or incomplete. The reader is therefore cautioned against assuming broad-based generalizations from these findings. The results are informative of the experience of a small group of first-time DMPA users seen by private practice physicians in three urban centers of Gujarat and are remarkably similar to results from a 1998 study of DMPA users conducted by the Population Council. 
All of the women in the study were married and the large majority (88\%) reported that their husbands had not been away for a single night during the last six months. The average age of the sampled women was 27 years. Relatively few women in this study have not attended any school and almost one-half (approximately 44\%) reported they had completed either high school or higher secondary, and an additional 24 percent had completed graduate or post-graduate school. The women in the study reported that their husbands' educational levels are comparable to their own. Almost all of the wives reported that their husbands are employed $(99.5 \%)$ most commonly in a petty business $(36 \%)$ or service industry position ( $42 \%)$.

The first-time DMPA users in this study have a low parity, with the average number of living children being 1.6 (SD plus or minus 0.9). Approximately one-quarter (27\%) of the women who recently began using DMPA reported that they desire to have another child. These findings suggest that the majority of the DMPA users either do not desire any more children or are undecided about their reproductive intentions. Slightly less than one-half of the first-time DMPA users $(41 \%)$ reported that since their last pregnancy they had tried another contraceptive method before switching to DMPA. The methods most frequently used before starting DMPA were the IUD (50\%) and oral contraceptives (34\%).

Approximately three out of every four first-time DMPA users reported that the first discussion to begin using DMPA was initiated by the physician. When asked to rate the degree to which they thought the physician had encouraged using DMPA, only 7 percent of the women said "very much" and over one-third (37\%) said the doctor had been neutral or even discouraging. Almost one-half (47\%) of the first-time DMPA users reported that the physician had encouraged her "somewhat." A minority of the women (30\%) who began using DMPA indicated that they would have preferred using another contraceptive method instead of DMPA. Among these women, the most frequently cited alternative method was the IUD $(57 \%)$ followed by oral contraceptives $(29 \%)$ and tubal ligation (9\%).

Only one-quarter (24\%) of the first-time DMPA users said that they had been advised about the

\section{Key Results form Survey of First- Time DMPA Users}

- Only 52 percent of the 352 DMPA users were successfully interviewed seven months after receiving the first dose; the high lost to follow-up rate limits the ability to generalize the findings.

- Clients in the study are older (mean age is 27 years) and fairly well educated ( $43 \%$ have completed level beyond secondary) and have used contraceptives before ( $41 \%$ since last pregnancy).

- About one-half (51\%) of the clients said that before beginning DMPA they were told about its side effects, and 62 percent were told about a warning sign (indicating a need to see a physician).

- Almost all of the DMPA users (91\%) correctly knew its effective use duration.

- Eighty-seven percent reported experiencing one or more side effects from DMPA (most commonly menstrual irregularities).

- Seventy percent of women who experienced side effects sought help from a physician.

- By the time of third dose only 27 percent of the first-time users continued with the method.

- Fifty-five percent of the DMPA discontinuers had successfully switched to another method.

- $\quad$ The seven-month DMPA discontinuation rate of 73 percent among women in this study is comparable to results from other follow-up studies of DMPA users conducted in Uttar Pradesh, India ( $81 \%$ at time of the $4^{\text {th }}$ dose) and the Philippines (69\% at 15 months).

- Results suggest that women in this study are willing to pay between Rs.55-84 for the DMPA injection, excluding consultation fees. 
possibility of switching to another method before starting to use DMPA. However, about one-half of the women (51\%) who began using DMPA during this study reported that they were told about the possible side effects before receiving the first injection. Less than onehalf $(41 \%)$ of the DMPA users said that they had been informed what to do if they experienced one or more of the side effects. The overall impression from these findings is that a slight majority of the women in this study received sufficient information on DMPA side effects before starting to use the method.

The side effect most frequently mentioned by DMPA users was spotting (40\%), followed by amenorrhoea (39\%), irregular menses and prolonged or heavy bleeding ( $27 \%$ each). The large majority of women who reported experiencing one or more side effects indicated that the condition was "very severe" as opposed to "somewhat severe." For example, almost all of the women who reported heavy bleeding (96\%) said the side effect was "very severe." The percentage of women reporting a side effect who sought help from a physician as a consequence of the condition was about 70 percent, with as many as 90 percent of the women who had prolonged or heavy bleeding saying that they went to seek medical help. Approximately 55 percent of the women who sought help from a physician for care of the side effect received a check-up and some type of medicine, and an additional 23 percent of the women who sought care reported they were told not to worry by the physician after the examination because the side effect was minor.

Among the 184 first-time users of DMPA who agreed to take part in this study, a little over half $(51 \%)$ had a second injection, and of those, about the same proportion (54\%) had a third injection. In total, 134 of the 184 first-time DMPA users (73\%) discontinued use of the injectable contraceptive after having one or two doses. The results from this study are comparable to the 1998 DMPA study conducted by the Population Council in Uttar Pradesh. In the 1998 study only 19 percent of the DMPA users continued to use the method at the time of the fourth dose. The continuation rate is also comparable to data from the Philippines where an operations research study conducted by the Population Council showed that by the end of a 15-month period, only 31 percent of the original cohort of DMPA users returned for a fifth injection. Clearly the DMPA method is not for all women or even a majority, but after a period of trial use it is reasonable to expect that about 20-30 percent of users will continue with the method. In this context, the ability to switch to another method is critically important.

Approximately one-half (55\%) of the women who stopped using DMPA had switched to another contraceptive method. The majority of these women $(51 \%)$ switched to another method within 15 days after discontinuing with the injectable method. At the time of the interview the large majority of the women who had stopped using DMPA but had begun using another method (85\%) were still using the same contraceptive method begun after DMPA. An additional 10 percent were still using family planning but had switched again to another contraceptive method. In all, only 60 of the 184 first-time DMPA users in this study (33\%) stopped using contraceptive methods entirely after discontinuing use of the injectable contraceptive method after the first, second or third dose.

The average amount paid by the DMPA users for a single ampule was Rs. 103, excluding the physician's consultation fees. This amount is substantially more than the Rs. 84 that women in the study indicated as the maximum reasonable amount that could be charged for the ampule. It is almost twice as much as the Rs. 55 that these women reported as being affordable to pay for a single DMPA ampule. 


\section{Recommendations}

The ability of this study to generate recommendations is limited by the special characteristics of the physicians who took part in the DKT India program in Gujarat, the high loss to followup rate among the DMPA clients, and the small sample size. Therefore the following points are offered as tentative recommendations for program managers to consider as they work towards expanding contraceptive choice for women in India.

- The DMPA injectable contraceptive should be offered through social marketing programs in India in conjunction with professional support services, such as IEC materials and professional development opportunities. OB/GYN specialists may be a more appropriate category of physicians for reaching women with family planning services in general.

- The price of DMPA should be reduced from the current procurement price of Rs. 75 per ampule that NGOs pay the supplier to an amount that provides a maximum retail price for the client of about Rs. 40-55.

- DMPA should be made available in multiple service delivery systems (e.g., other than social marketing or private sector settings) that can ensure provider technical competence and informed choice, including the provision of other temporary methods. 


\section{Table of Contents}

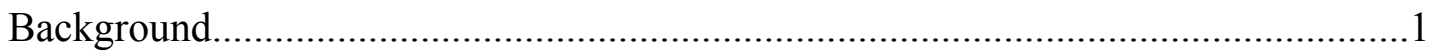

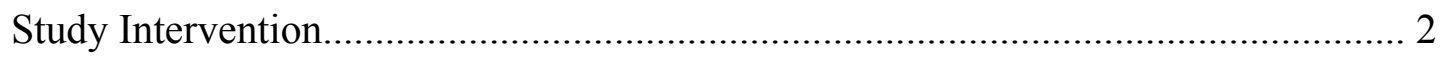

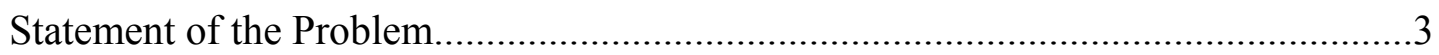

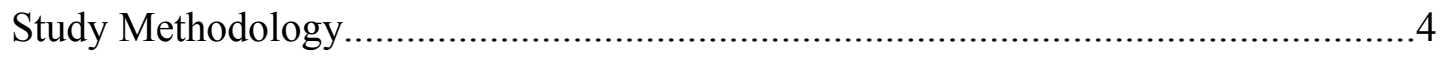

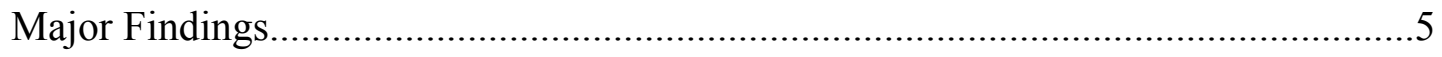

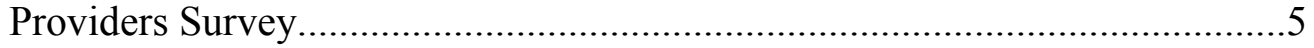

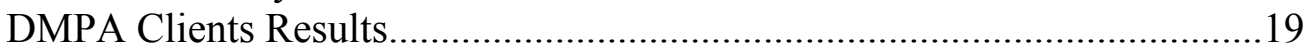



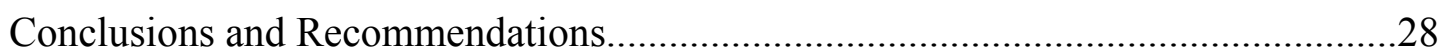

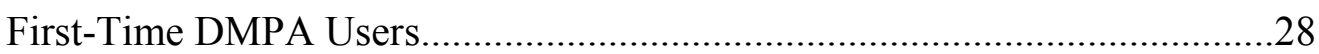

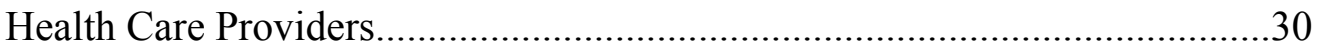

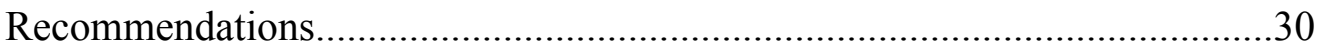




\section{List of Tables}

Table 1: $\quad$ Age distribution of the private practitioners enrolled in DMPA project by place of practice, sex, and specialty

Table 2: $\quad$ Private practitioners' years of experience and type of health services provided by place of practice, sex, and specialty

Table 3: $\quad$ Staff available in the clinics of the private practitioners

Table 4: $\quad$ Family planning service delivery characteristics

Table 5: $\quad$ Participation in the EngenderHealth seminars

Table 6: Number of DMPA clients reported by physicians in the study

Table 7: Physicians' knowledge about timing and mechanism of action

Table 8: $\quad$ Physicians' knowledge about the advantages of DMPA

Table 9: $\quad$ Physicians' knowledge of the disadvantages and side effects of DMPA

Table 10: Physicians' knowledge of managing bleeding problems caused by DMPA

Table 11: $\quad$ Major contraindications to DMPA reported by physicians

Table 12: $\quad$ Sample results of first-time DMPA clients

Table 13: $\quad$ Socio-demographic characteristics of the acceptors of DMPA

Table 14: $\quad$ Past pregnancies and future intentions

Table 15: $\quad$ Percentage of women reporting information given at the time of first injection

Table 16: $\quad$ Nature of side effects experienced by DMPA users after first, second or third doses

Table 17: $\quad$ Use of other contraceptive methods after stopping DMPA

Table 18: $\quad$ Cost of DMPA (Rs.) reported by users 


\section{List of Figures}

Figure 1: $\quad$ Average case load of private medical practitioners by selected background characteristics

Figure 2: $\quad$ Reported changes in medical practice by physicians participating in the study

Figure 3: Have you ever counseled a patient about, or provided an injectable contraceptive to one of your patients?

Figure 4: $\quad$ Provision of DMPA by physicians in the study

Figure 5: $\quad$ Reported cost paid for a single DMPA ampule by physicians

Figure 6: $\quad$ Reproductive history of first-time DMPA users

Figure 7: $\quad$ Contraceptive use dynamics since the last pregnancy

Figure 8: Who initiated the discussion about beginning to use DMPA?

Figure 9: $\quad$ Contraceptive method preference at time of first DMPA use

Figure 10: Number of side effects DMPA users experienced after first, second and third doses

Figure 11: Continuation of DMPA after the first dose 


\section{BACKGROUND}

The national family welfare program in India does not currently include injectable contraceptives in its mix of contraceptive methods offered in public sector clinics. Although both types of injectable contraceptives (NetEn and DMPA) are approved for commercial sale by the Drug Controller of India and are available with a doctor's prescription, the Ministry of Health and Family Welfare has not begun routine procurement of either contraceptive method. There has not been a large body of research on the use dynamics of injectable contraceptives in India that could be used to guide policy decisions on the addition of the method. The few studies that have been conducted indicate positive results and are hence suggestive of an important role the method could assume in the national family planning program.

Pharmacia \& Upjohn conducted a "Post Marketing Surveillance Study on Injection DepoProvera" 3 that was designed to assess the safety and acceptability of DMPA among a sample of 1,079 women. The large majority of these women (84.2\%) continued with the method through five doses. Side effects were common, as almost 80 percent of the subjects in this study reported experiencing one or more medical events during the study period, though only three of these cases were considered serious. The conclusion from this 1999 study is that "DMPA $150 \mathrm{mg}$ is a safe and effective contraceptive, and that sufficient pre-treatment counseling on the expected hormonal effects will greatly increase the acceptability of this method of contraception" (PMS Final Report, page 2).

In 1998 the Population Council's Asia and the Near East OR/TA Project conducted an operations research study on the effect of price changes on perceptions and use of DMPA in Uttar Pradesh in association with Parivar Seva Sanstha. ${ }^{4}$ This study examined patterns of use when three different prices were charged for the DMPA method in the clinics of an affiliate of Marie Stopes International. Although overall continuation with the method was observed to be low, with less than one-fifth (19\%) of the women continuing through four doses, users' perceptions were positive and those who could not tolerate a side effect were able to switch to another, more acceptable method. A wholesale price of Rs. 35 was estimated as being the most affordable price for the DMPA in the setting of this study. These two studies are recent investigations into the use dynamics of DMPA in India.

Public debate on injectable contraceptives is still characterized by strident rhetoric that often polarizes discussions. This has restricted the implementation of a large-scale, national program for injectable contraceptives in India. However, many public, NGO and private sector service delivery systems are suitably matched to the requirements of providing injectable contraceptives, including the ability to ensure choice and service delivery quality. This operations research study was designed to demonstrate the feasibility of providing injectable contraceptives in private medical practices and to contribute to the body of scientific literature on the acceptability of this method in India.

\footnotetext{
3 "Post Marketing Surveillance Study of Injectable Contraceptive Depo-Provera in Indian Women," R. P. Soonawala, David Zambrano and F. Tam. Pharmacia \& Upjohn. October 8, 1999. New Delhi, India.

4 "Analysis of Price Change on the Perceptions and Use of DMPA among Clients Using Reproductive Health Services in Uttar Pradesh, India." Leila Caleb-Varkey, John W. Townsend, Sneh Vishwanath and Sudha Tewari. The Population Council. March 27, 1998. New Delhi, India.
} 


\section{STUDY INTERVENTION}

The conduct of operations research to investigate issues surrounding the introduction of DMPA into a family planning system required the participation of partner agencies that bring specialized skills and services. The study required two essential components for its intervention: 1) access to a fairly large number of physicians supported by a contraceptive distribution system that includes DMPA in its method mix; and 2) training and supportive supervision skills to ensure good quality counseling and informed choice of the injectable contraceptive method. Two leading international agencies formed a partnership to conduct this operations research study: DKT India and EngenderHealth.

\section{DKT India}

The DKT social marketing programs in India have been at the forefront of exploring alternative contraceptive options and delivery systems. DKT India is a leader in this field and has a proven record in establishing sustainable marketing systems for oral contraceptives and condoms (among other products) in several states. DKT India first included injectable contraceptives in its program in 1996 when NetEn was piloted in a social marketing project in Maharashtra and Gujarat. In 1999, the distributor of DMPA in India, Pharmacia \& Upjohn, began to offer the contraceptive at Rs. 70 to NGOs (down from the commercial rate of Rs. 150 per ampule). This reduced price brought the method within affordable range for social marketing programs, and in 1998 and 1999 DKT began to introduce the method into its programs in Maharashtra and Gujarat. DKT was acutely aware of the concerns from special interest groups in India about ensuring informed choice of the injectable contraceptive and had built into its program from the beginning an investment in IEC materials and supportive supervision by regional sales representatives and state level IEC officers. The partnership with FRONTIERS was an extension of their program to bring the additional benefit of information on use dynamics and provider motivation.

DKT India was responsible for contacting approximately 100 private practice providers in Ahmedabad, Baroda and Surat (this number was increased by EngenderHealth in the process of arranging for the professional seminars) about participating in the study. In addition to assisting in identifying participating physicians, DKT India provided an uninterrupted source of DMPA injectable contraceptives at a subsidized price of Rs. 40 to their stockists (small, local pharmaceutical providers who are associated with the DKT India program). Through the network of DKT India sales representatives and IEC program officers in Gujarat, DKT India also assisted in the distribution of IEC materials produced by EngenderHealth.

\section{EngenderHealth}

The study identified the need to ensure a baseline level of good communication practices that are conducive to improved counseling about DMPA as a critically important element of the study. In addition, there was a concern about ensuring a standard level of technical knowledge among all the providers in the study. A partnership was formed with EngenderHealth in India to organize these two aspects of the study and to coordinate the design and implementation of the professional development seminars and IEC material production with DKT India and FRONTIERS. Funds for the EngenderHealth organized activities were provided through the Population Council's Expanding Contraceptive Choice program. A final report is available from EngenderHealth and the Population Council providing detailed information on the activities carried out by EngenderHealth under this subagreement. This section of the operations 
research final report provides an overview of the principal accomplishments in the training and supervision of the private practice providers who participated in the study.

EngenderHealth developed and field tested training materials for physicians and paramedical staff in collaboration with DKT India during October 1999. As part of this collaboration these two agencies produced a series of IEC materials on DMPA that included a client take-away brochure, an awareness-raising poster, a self-instructional flip chart for use in physicians' waiting rooms, and laminated instruction sheets for physicians (specifying technical points about the method, including contraindications, side effects and their management). The client-oriented materials were translated into Gujarati and Hindi and printed by DKT, and then distributed by DKT sales representatives to all of the participating physicians after their training program.

The study originally called for a series of two-day in-service training programs for the private practice physicians. However, it soon proved impossible to convene these physicians for more than a one-day (six hour) session because almost all were unavailable or unwilling to close their practices for more than one day. Therefore, EngenderHealth, working with locally recruited and respected consultants, organized eight one-day training programs that functioned as a type of professional development seminar for the 241 physicians. Among these physicians, 159 agreed

to participate in the operations research study at the end of the seminar. As a consequence of the reduced number of days devoted to upgrading the physicians' communication and technical practices, the study decided to concentrate remaining resources on enhancing the supervision skills of the DKT India sales representatives and IEC officers. EngenderHealth conducted a one-day training session for 43 DKT staff between January and May 2000. This short course was designed to upgrade the technical knowledge and communication skills related to DMPA and to provide practical guidance to the DKT India sales force on how to interact with physicians on the need to ensure informed choice of DMPA. In addition to conducting the training programs for physicians and DKT India staff, EngenderHealth staff and consultants also conducted follow-up visits with all 159 physicians who took part in the seminars between February and June 2000. These follow-up visits served to ensure that the physicians received a continuous supply of DMPA, to facilitate proper infection prevention and safe disposal of sharps, and to address any questions that the physicians raised about DMPA or the study.

\section{STATEMENT OF THE PROBLEM}

The overall goal of the proposed project was to expand the availability of contraceptives in India, particularly temporary contraceptives. The study sought to demonstrate the feasibility of providing the DMPA injectable contraceptive to private sector medical clients in a manner that promotes informed choice, adheres to good technical quality, and supports sustained use by satisfied clients. Prior to this study there had not been a follow-up investigation of firsttime DMPA users from private practice medical settings in India.

The long-term goal of this study is to ultimately contribute to the reduction of maternal mortality and morbidity in India through an increase in contraceptive practice/contraceptive choice. The following are the short term or immediate objectives of the study:

1. The study will demonstrate the feasibility of providing the DMPA injectable contraceptive to private sector clients in a manner that promotes informed choice, adheres to good technical quality and supports sustained use by satisfied clients. 
2. The study will identify factors that motivate private sector physicians to provide injectable contraceptives in a manner consistent with high quality counseling and technical expertise.

\section{STUDY METHODOLOGY}

The research utilized a post-test only, uncontrolled study design that retrospectively investigated the contraceptive practices of all first-time DMPA users in private practice settings that participate in the DKT India contraceptive social marketing program in Gujarat. Physicians were able to purchase DMPA contraceptives from DKT India suppliers at a subsidized rate of Rs. 40 (commercially available DMPA is sold for approximately Rs. 150). In addition to purchasing the DMPA at a reduced rate, the physicians also benefited from promotional and IEC materials produced by the study, and regular visits by sales representatives and other representatives of DKT India. Three sites were purposively selected for the study: Ahmedabad, Baroda and Surat. At the time of the study design these were the principal locations of the DKT program in Gujarat.

There were three conditions placed on the physicians who agreed to take part in the study that were outlined in an informed consent statement administered by EngenderHealth and DKT India staff before enrolling any physician in the study. First, they had to participate in a day-long professional seminar on interpersonal communication/counseling techniques and a contraceptive technology update on DMPA, organized by EngenderHealth. Second, the physicians had to agree to request the consent of all first-time DMPA users for a follow-up interview seven months later, and to record sufficient locater information on a specially-designed client locator card to conduct the home interview. Third, the physicians agreed to a short interview conducted in their office approximately six months after the EngenderHealth professional seminar.

A very modest one-time stipend was paid to all of the physicians to ensure that they recorded locator information (the same amount was paid regardless of the number of DMPA clients enrolled in the study). The original proposal called for 100 physicians to be enrolled in the study, but once field operations began, this number was expanded to 159 (in order to achieve a larger sample of first-time DMPA users), and later dropped to 158 when one physician moved.

Physicians who participated in the study conveyed to all first-time DMPA users a standardized informed consent statement (written in Gujarati and Hindi) that outlined the principal objectives of the study, described the follow-up interview at the woman's home in seven months (i.e., after receiving three doses of DMPA), and asked for her permission to record her name and contact information. DMPA clients were considered eligible for the study if they had never used an injectable contraceptive previously (but could have used another contraceptive method), were resident in the nearby vicinity of the physician's practice, and had the intention to remain at their present address for 9-12 months. Client enrollment began on April 1, 2000 and continued through September 30, 2001. Representatives of CORT collected the client enrollment cards on a monthly basis throughout the enrollment period.

A subagreement was issued to CORT for the organization and conduction of the client and provider surveys. The study's six-month data collection period began fieldwork operations on November 1, 2000 and continued without interruption until late January 2001. All of the firsttime DMPA users who enrolled in the study during April-June 2000 and approximately 75 percent of the 158 providers had been contacted for interviews by that date. On January 26, 2001, a severe earthquake occurred in Gujarat, devastating many areas of the state and 
substantially damaging large portions of Ahmedabad and Surat, with less physical destruction in Baroda. The earthquake had multiple effects on the client follow-up study, primarily through the profound disruption to daily life even in the study areas that were not directly afflicted with the destruction. These overwhelming environmental effects caused the follow-up interview period to be truncated and the elimination of all clients from the study who had been enrolled between July and October 2001. The remaining interviews with physicians continued after a pause, as the remainder of these cases were in Baroda and other areas less affected by the earthquake, and the indicators measured in the provider survey were less likely to be disrupted.

\section{MAJOR FINDINGS}

\section{Provider Survey}

\section{Background Characteristics}

In all, 158 private practice physicians who participated in the DKT-sponsored contraceptive social marketing program in Gujarat agreed to participate in the study of DMPA use dynamics. This section reviews the principal findings from a survey of these providers conducted 9-12 months after they attended a training session on interpersonal communication techniques and a contraceptive technical update on DMPA.

Table 1: Age distribution of the private practitioners enrolled in DMPA project by place of practice, sex, and specialty (percentage)

\begin{tabular}{|c|c|c|c|c|c|c|c|c|}
\hline & \multicolumn{3}{|c|}{ Location } & \multicolumn{2}{|c|}{ Sex } & \multicolumn{2}{|c|}{ Specialty } & \multirow{2}{*}{$\begin{array}{c}\text { Total } \\
(n=139)\end{array}$} \\
\hline & $\begin{array}{c}\text { Ahmedabad } \\
\quad(n=34)\end{array}$ & $\begin{array}{c}\text { Baroda } \\
(\mathrm{n}-57)\end{array}$ & $\begin{array}{c}\text { Surat } \\
(n=48)\end{array}$ & $\begin{array}{l}\text { Male } \\
(n=7)\end{array}$ & $\begin{array}{c}\text { Female } \\
(n=68)\end{array}$ & $\begin{array}{l}\text { MBBS } \\
(n=56)\end{array}$ & $\begin{array}{c}\text { OB/GYN } \\
(n=83)\end{array}$ & \\
\hline \multicolumn{9}{|l|}{$\begin{array}{l}\text { Age } \\
\text { distribution } \\
\text { (in years) }\end{array}$} \\
\hline $20-29$ & 9 & - & - & - & 4 & - & 4 & 2 \\
\hline $30-39$ & 47 & 32 & 23 & 34 & 31 & 36 & 30 & 32 \\
\hline $40-49$ & 21 & 40 & 42 & 41 & 31 & 36 & 36 & 36 \\
\hline $50-59$ & 21 & 23 & 31 & 24 & 27 & 27 & 24 & 25 \\
\hline $60-69$ & 3 & 5 & 4 & 1 & 7 & 2 & 6 & 4 \\
\hline Mean Age & 40 & 45 & 46 & 44 & 44 & 44 & 44 & 44 \\
\hline $\begin{array}{l}\text { Range } \\
\text { (Min-Max) }\end{array}$ & $26-62$ & $30-65$ & $34-68$ & $30-60$ & $26-68$ & $30-60$ & $26-68$ & $26-68$ \\
\hline TOTAL \% & $24 \%$ & $41 \%$ & $35 \%$ & $51 \%$ & $49 \%$ & $40 \%$ & $60 \%$ & $100 \%$ \\
\hline
\end{tabular}

Approximately 88 percent of these physicians $(n=139)$ were successfully contacted and completed the interviews during this study. Among the 19 physicians who did not fully respond to the interviews, two ( $1 \%$ of the total sample) refused to answer the interviewer's questions, one could not be contacted $(0.6 \%$ of the total sample), one physician had passed away $(0.6 \%$ of the total sample), and 15 had moved out of the study sites and were lost to follow-up (approximately 10\% of the total sample). Overall, the response rate in the study was strong and there is no indication that the missing 12 percent of the original sample in any way substantially biases the results presented here. 
Table 2: Private practitioners' years of experience and type of health services provided by place of practice, sex, and specialty (percentage)

\begin{tabular}{|c|c|c|c|c|c|c|c|c|}
\hline & \multicolumn{3}{|c|}{ Location } & \multicolumn{2}{|c|}{ Sex } & \multicolumn{2}{|c|}{ Specialty } & \multirow{2}{*}{$\begin{array}{c}\text { Total } \\
(n=139)\end{array}$} \\
\hline & $\begin{array}{c}\text { Ahmedabad } \\
(n=34)\end{array}$ & $\begin{array}{c}\text { Baroda } \\
(n=57)\end{array}$ & $\begin{array}{c}\text { Surat } \\
(n=48)\end{array}$ & $\begin{array}{c}\text { Male } \\
(n=71)\end{array}$ & $\begin{array}{c}\text { Female } \\
(n=68)\end{array}$ & $\begin{array}{l}\text { MBBS } \\
(n=56)\end{array}$ & $\begin{array}{c}\text { OB/GYN } \\
(n=83)\end{array}$ & \\
\hline \multicolumn{9}{|l|}{$\begin{array}{l}\text { Years of providing } \\
\text { health services }\end{array}$} \\
\hline $1-5$ & 21 & 2 & 2 & 4 & 9 & 4 & 8 & 6 \\
\hline $6-10$ & 23 & 17 & 10 & 15 & 18 & 18 & 16 & 16 \\
\hline $11-20$ & 38 & 47 & 48 & 51 & 40 & 45 & 46 & 45 \\
\hline $21-30$ & 15 & 28 & 29 & 25 & 25 & 29 & 23 & 25 \\
\hline 31 and more & 3 & 5 & 10 & 4 & 9 & 5 & 7 & 6 \\
\hline $\begin{array}{l}\text { Mean number of } \\
\text { years }\end{array}$ & 14 & 18 & 19 & 17 & 17 & 18 & 17 & 17 \\
\hline Range (Min-Max) & $1-34$ & $2-40$ & $5-36$ & $4-34$ & $1-40$ & $2-34$ & $1-40$ & $1-40$ \\
\hline \multicolumn{9}{|l|}{$\begin{array}{l}\text { Years of providing } \\
\text { health services in } \\
\text { private practice }\end{array}$} \\
\hline $1-5$ & 23 & 16 & 12 & 14 & 19 & 14 & 18 & 16 \\
\hline $6-10$ & 35 & 39 & 21 & 31 & 32 & 23 & 37 & 32 \\
\hline $11-20$ & 29 & 30 & 44 & 38 & 31 & 41 & 30 & 34 \\
\hline $21-30$ & 12 & 14 & 21 & 17 & 15 & 21 & 12 & 16 \\
\hline 31 and more & - & 2 & 2 & - & 3 & - & 2 & 1 \\
\hline $\begin{array}{l}\text { Mean number of } \\
\text { years }\end{array}$ & 11 & 13 & 15 & 13 & 13 & 14 & 12 & 13 \\
\hline Range (Min-Max) & $1-30$ & $1-40$ & $2-36$ & $1-30$ & $1-40$ & $2-29$ & $1-40$ & $1-40$ \\
\hline \multicolumn{9}{|l|}{$\begin{array}{l}\text { Years of practicing } \\
\text { in current setting }\end{array}$} \\
\hline $1-5$ & 30 & 14 & 23 & 18 & 23 & 20 & 22 & 21 \\
\hline $6-10$ & 35 & 37 & 17 & 31 & 28 & 23 & 34 & 29 \\
\hline $11-20$ & 23 & 37 & 46 & 38 & 35 & 43 & 32 & 37 \\
\hline $21-30$ & 12 & 10 & 15 & 13 & 12 & 14 & 11 & 12 \\
\hline 31 and more & - & 2 & - & - & 1 & - & 1 & 1 \\
\hline $\begin{array}{l}\text { Mean number of } \\
\text { years }\end{array}$ & 10 & 13 & 12 & 12 & 12 & 12 & 11 & 12 \\
\hline Range (Min-Max) & $1-30$ & $1-40$ & $1-30$ & $1-30$ & $1-40$ & $1-29$ & $1-40$ & $1-40$ \\
\hline $\begin{array}{l}\text { Percent providing } \\
\text { honorary medical } \\
\text { services to hospital } \\
\text { or medical clinics }\end{array}$ & 38 & 35 & 25 & 28 & 37 & 16 & 43 & 32 \\
\hline \multicolumn{9}{|l|}{$\begin{array}{l}\text { Provision of } \\
\text { medicine }\end{array}$} \\
\hline $\begin{array}{l}\text { Prescribing } \\
\text { medicine only }\end{array}$ & 71 & 46 & 44 & 38 & 65 & 18 & 73 & 51 \\
\hline $\begin{array}{l}\text { Both prescribing } \\
\text { and dispensing }\end{array}$ & 29 & 54 & 56 & 62 & 35 & 82 & 27 & 49 \\
\hline
\end{tabular}

The sample of physicians was nearly evenly divided by gender: 71 of the respondents were male and 68 were female. Almost two-thirds $(60 \%, \mathrm{n}=83)$ were OB/GYN specialists and all 
of the others $(40 \%, \mathrm{n}=56)$ were MBBS, or generalists. Among the OB/GYN specialists, 69 percent were female, whereas most $(80 \%)$ of the MBBS physicians were male (Table 1$)$. Approximately two-thirds of the physicians in the study were between the ages of 30 and 49 and an additional one-quarter were between the ages of 50 and 59. There is no significant difference in the age of physicians by sex or specialty, but the physicians from Ahmedabad were somewhat younger than those from Surat or Baroda.

The average length of time that physicians in this sample had been providing medical services was quite long (17.4 years), corresponding to the middle-aged characteristic of the sample's majority (Table 2). The average length of time a physician in the sample had been working in the private practice setting where the interview took place was about 12 years. Physicians from Ahmedabad had been providing health care services for a shorter length of time (in general, and in the current setting) than providers in the other two study sites, reflecting their younger age (Table 1). Otherwise, there are no apparent differences in the length of time that physicians have been practicing medicine in any type of setting by their sex or specialty.

\section{Figure 1: Average case load of private medical practitioners by selected background characteristics}

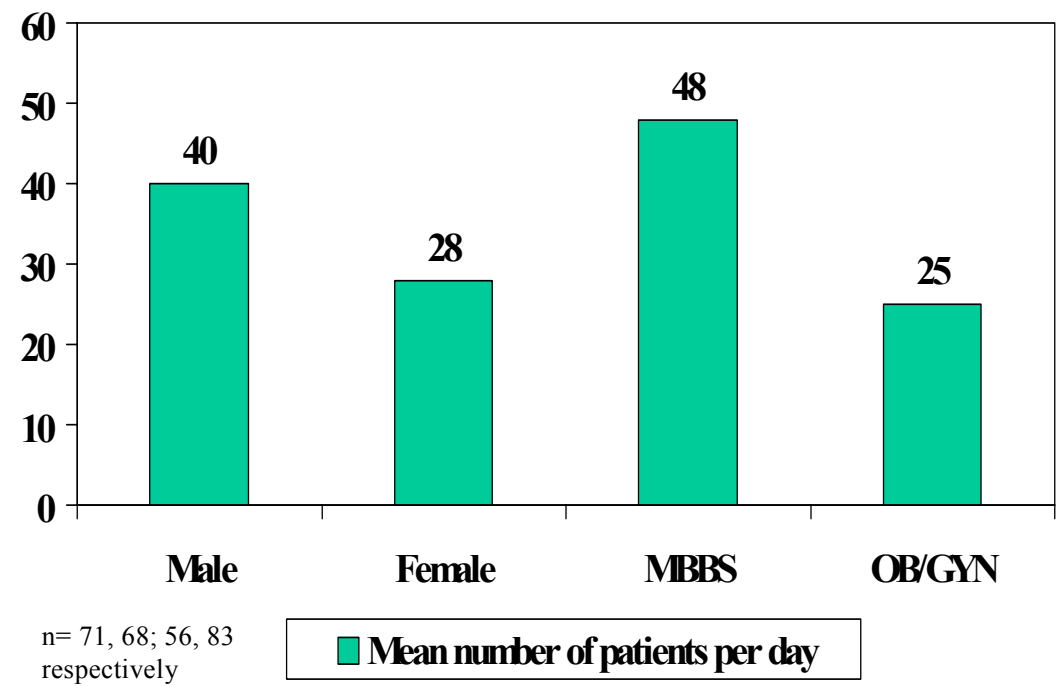

The percentage of physicians who currently provide honorary medical services differs by the location of their practice: physicians from Ahmedabad are more likely to provide pro bono care $(38 \%)$ than physicians from Surat $(25 \%)$ or Baroda $(35 \%)$. In addition, female physicians are more likely than male physicians to provide honorary medical care $(37 \%$ versus $28 \%$, respectively), as are OB/GYN specialists as opposed to MBBS physicians (43\% versus $16 \%$ ). Although in general the sample is almost evenly divided between physicians who only prescribe medicine (51\%) and those who both prescribe and dispense medicine (including contraceptive methods such as the IUD, pills and DMPA injections) (49\%), there are important differences according to the location of the physician's practice, their sex and specialty. Physicians in Ahmedabad were more likely to only prescribe medicine $(70 \%)$ than their peers in Baroda (46\%) or Surat (44\%). Male physicians were less likely to only prescribe medicine $(38 \%)$ than female physicians $(65 \%)$, which is also reflected in the finding 
that $\mathrm{OB} / \mathrm{GYN}$ physicians (who are predominately female) are more likely to prescribe only $(74 \%)$ than MBBS physicians (18\%).

The average case load of the physicians in the study varied according to their type of specialty and sex: the predominately male MBBS physicians reported a higher daily case load (mean number of patients per day $=40.4$ for male providers and 47.9 for MBBS providers) than the predominately female $\mathrm{OB} / \mathrm{GYN}$ providers (mean number of patients per day $=28.4$ for female providers and 25.5 for $\mathrm{OB} / \mathrm{GYN}$ specialists). In general, the providers in these settings have a high caseload, particularly considering that most operate in a singlepractitioner clinic without secretarial or nursing support (Table 3 ).

Approximately two-thirds of the physicians in this study (66\%) work in a solo-practice setting, with almost all of the MBBS physicians $(91 \%)$ working alone. Anecdotal evidence indicates that in settings where there are two physicians (approximately onequarter of the sample), they are husband and wife. Table 3 reports that settings with more than one physician are most likely to be $\mathrm{OB} / \mathrm{GYN}$ practices. The majority of the practices do employ a nurse $(60 \%)$, but a high percentage do not have nursing staff (approximately 40\%).

While MBBS providers are least likely to have any nursing staff in their practice, they are almost as likely to have an administrative support person in their clinic as an $\mathrm{OB} / \mathrm{GYN}$ specialist.

However, OB/GYN specialists are more likely to have more nurses and administrative staff (mean of 3.5 and 2.2 per physician, respectively) than an MBBS provider (mean of 2.1 and 1.3 , respectively, per physician).
Table 3: Staff available in the clinics of the private practitioners (percentage)

\begin{tabular}{|c|c|c|c|}
\hline Staff distribution & $\begin{array}{l}\text { MBBS } \\
(n=56)\end{array}$ & $\begin{array}{c}\text { OB/GYN } \\
(n=83)\end{array}$ & $\begin{array}{c}\text { Total } \\
(n=139)\end{array}$ \\
\hline Number of doctors & & & \\
\hline 1 & 91 & 49 & 66 \\
\hline 2 & 5 & 35 & 23 \\
\hline 3 & 4 & 8 & 6 \\
\hline 4 and more & - & 7 & 4 \\
\hline Mean & 1 & 2 & 1 \\
\hline Range (Min-Max) & $1-3$ & $1-4$ & $1-4$ \\
\hline Number of nurses & & & \\
\hline None & 75 & 17 & 40 \\
\hline 1 & 9 & 13 & 11 \\
\hline 2 & 11 & 14 & 13 \\
\hline 3 & 2 & 25 & 16 \\
\hline 4 and more & 4 & 30 & 19 \\
\hline Mean & 2 & 3 & 3 \\
\hline Range (Min-Max) & $1-5$ & $1-11$ & $1-11$ \\
\hline $\begin{array}{l}\text { Number of administrative } \\
\text { staff }\end{array}$ & & & \\
\hline None & 62 & 53 & 57 \\
\hline 1 & 29 & 23 & 25 \\
\hline 2 & 7 & 11 & 9 \\
\hline 3 and more & 2 & 13 & 9 \\
\hline Mean & 1 & 2 & 2 \\
\hline Range (Min-Max) & $1-4$ & $1-8$ & $1-8$ \\
\hline
\end{tabular}

\section{Family Planning Service Provision}

The physicians in this study cannot be characterized as "family planning service providers." They are all for-profit private practice physicians whose clinical practice involves either general primary care services (principally curative services) for the MBBS physicians, or obstetrical care for the OB/GYN specialists. These providers operate out of small clinics, usually consisting of a waiting area and a single consultation room without laboratory facilities on site. The provision of contraceptive methods is a complementary service that is 
provided to their patients. The results presented in Table 4 show that family planning services are more likely to be provided by the OB/GYN specialists than the MBBS:

approximately three out of every four OB/GYN specialists $(76 \%)$ reported that they provide a full range of family planning services to their patients as opposed to fewer than one in every $10(7 \%)$ of the MBBS physicians.

Table 4: Family planning service delivery characteristics (percentage)

\begin{tabular}{|c|c|c|c|}
\hline & $\begin{array}{l}\text { MBBS } \\
(n=56)\end{array}$ & $\begin{array}{c}\text { OB/GYN } \\
(n=83)\end{array}$ & $\begin{array}{c}\text { Total } \\
(\mathrm{n}=139)\end{array}$ \\
\hline \multicolumn{4}{|l|}{ Type of FP services currently provided* } \\
\hline Counseling/giving information & 68 & 13 & 35 \\
\hline Perform tubectomy & - & 16 & 9 \\
\hline Prescribe OCP & 54 & 18 & 32 \\
\hline Provide IUD, OCP, DMPA, Condom method & 32 & 10 & 19 \\
\hline All of the above services & 7 & 76 & 48 \\
\hline None of the above services & 4 & - & 1.4 \\
\hline \multicolumn{4}{|l|}{$\begin{array}{l}\text { Person who initiates talk about FP during the } \\
\text { consultation }\end{array}$} \\
\hline Patient & 29 & 18 & 22 \\
\hline Provider & 25 & 26 & 26 \\
\hline Both & 43 & 55 & 50 \\
\hline Not providing FP services & 4 & - & 1 \\
\hline \multicolumn{4}{|l|}{ Proportion of patients reportedly counselled on FP } \\
\hline $1-10$ & 43 & 12 & 24 \\
\hline $11-20$ & 16 & 18 & 17 \\
\hline $21-50$ & 25 & 30 & 28 \\
\hline $51-75$ & 5 & 7 & 6 \\
\hline$>75$ & 5 & 22 & 15 \\
\hline Don’t know/can’t say & 2 & 11 & 7 \\
\hline Not providing any FP services & 4 & - & 1 \\
\hline Mean $\%$ of patients counseled on FP & 25 & 43 & 36 \\
\hline
\end{tabular}

* Multiple responses possible

However, almost two-thirds of the MBBS physicians (68\%) indicated that they do provide family planning counselling to their patients. Approximately one-half of all the physicians in the study reported that both the patient and the provider are equally likely to initiate discussions about the use of family planning during the consultation. Important differences emerge from the findings in the overall proportion of patients that the physicians reported as usually receiving family planning information. Forty-two percent of patients seen by OB/GYN specialists are told about family planning, whereas only 25 percent of the MBBS physicians' patients received this information. Overall, the physicians report that about onethird of their patients routinely receive information about family planning methods and services. This finding reinforces the anecdotal evidence that this study's sample is not strongly oriented toward the provision of family planning services.

\section{Participation in the EngenderHealth Seminars}

Each of the physicians took part in one or more of the professional seminars organized by EngenderHealth (described previously in this report). The principal reasons given by the physicians for participating in the seminars and their appreciation of these meetings are indicated in Table 5. 
Table 5: Participation in the EngenderHealth seminars (percentage)

\begin{tabular}{|c|c|c|c|c|c|c|}
\hline & \multicolumn{3}{|c|}{ Location } & \multicolumn{2}{|c|}{ Specialty } & \multirow{2}{*}{$\begin{array}{l}\text { Total } \\
(n=139)\end{array}$} \\
\hline & $\begin{array}{c}\text { Ahmedabad } \\
\qquad(n=34)\end{array}$ & $\begin{array}{c}\text { Baroda } \\
(n=57)\end{array}$ & $\begin{array}{c}\text { Surat } \\
(n=48)\end{array}$ & $\begin{array}{l}\text { MBBS } \\
(n=56)\end{array}$ & $\begin{array}{c}\text { OB/GYN } \\
(n=83)\end{array}$ & \\
\hline $\begin{array}{l}\text { Motivating reason to get involved in } \\
\text { DMPA OR study* } \\
\text { It's a new method } \\
\text { For more knowledge about FP } \\
\text { program } \\
\text { Peer pressure } \\
\text { Excellent information for me and } \\
\text { my patients } \\
\text { Respect for EngenderHealth } \\
\text { Convenient method/easy to use/low } \\
\text { failure rate } \\
\text { Want a reliable method for lactating } \\
\text { mother/for women's health } \\
\text { Self interest } \\
\text { Better way of FP } \\
\text { Had time to attend when } \\
\text { representative requested }\end{array}$ & $\begin{array}{c}21 \\
6 \\
38 \\
3 \\
\\
3 \\
18 \\
3 \\
\\
9 \\
9 \\
-\end{array}$ & $\begin{array}{c}19 \\
23 \\
9 \\
12 \\
\\
16 \\
3 \\
3 \\
\\
9 \\
5 \\
3\end{array}$ & $\begin{array}{c}23 \\
25 \\
8 \\
21 \\
\\
8 \\
10 \\
\\
2 \\
\\
- \\
2 \\
8\end{array}$ & $\begin{array}{c}20 \\
23 \\
5 \\
21 \\
\\
12 \\
5 \\
\\
- \\
\\
2 \\
7 \\
7\end{array}$ & $\begin{array}{c}22 \\
17 \\
\\
23 \\
7 \\
\\
8 \\
12 \\
\\
5 \\
\\
8 \\
4 \\
2\end{array}$ & $\begin{array}{c}21 \\
19 \\
16 \\
13 \\
10 \\
9 \\
3 \\
\\
6 \\
5 \\
4\end{array}$ \\
\hline $\begin{array}{l}\text { Usefulness of the EngenderHealth } \\
\text { information session } \\
\text { Very useful } \\
\text { Somewhat useful } \\
\text { Not useful } \\
\text { Can't say }\end{array}$ & $\begin{array}{c}65 \\
35 \\
- \\
-\end{array}$ & $\begin{array}{c}65 \\
30 \\
3 \\
2\end{array}$ & $\begin{array}{c}60 \\
37 \\
2 \\
-\end{array}$ & $\begin{array}{c}70 \\
25 \\
4 \\
2\end{array}$ & $\begin{array}{c}59 \\
40 \\
1 \\
-\end{array}$ & $\begin{array}{c}63 \\
34 \\
2 \\
1\end{array}$ \\
\hline $\begin{array}{l}\text { Reason for considering course } \\
\text { useful/ not useful } \\
\text { Informative/more knowledge/latest } \\
\text { knowledge } \\
\text { Have new option for patient } \\
\text { Low failure rate/few side } \\
\text { effects/safe and convenient method } \\
\text { Easy for the patients } \\
\text { We can use all methods } \\
\text { Patients refuse to take injection } \\
\text { Useful for doctor to know } \\
\text { It has side effects } \\
\text { Lengthy sessions/not for OB/GYN } \\
\text { specialist } \\
\text { No response }\end{array}$ & $\begin{array}{c}59 \\
15 \\
- \\
- \\
15 \\
3 \\
- \\
- \\
- \\
9\end{array}$ & $\begin{array}{c}46 \\
5 \\
5 \\
16 \\
\\
9 \\
3 \\
12 \\
- \\
3 \\
3 \\
\\
7\end{array}$ & $\begin{array}{c}54 \\
12 \\
8 \\
4 \\
8 \\
6 \\
8 \\
- \\
- \\
6\end{array}$ & $\begin{array}{c}48 \\
5 \\
19 \\
12 \\
- \\
12 \\
4 \\
4 \\
- \\
4\end{array}$ & $\begin{array}{c}54 \\
13 \\
2 \\
- \\
13 \\
5 \\
2 \\
- \\
2 \\
10\end{array}$ & $\begin{array}{c}52 \\
10 \\
9 \\
\\
5 \\
8 \\
8 \\
3 \\
1 \\
1 \\
7\end{array}$ \\
\hline $\begin{array}{l}\text { Percent practitioners agreeing that } \\
\text { participating in programs like this } \\
\text { enhances their professional growth } \\
\text { Agree } \\
\text { Neutral } \\
\text { Disagree } \\
\text { Strongly disagree } \\
\text { Not recorded }\end{array}$ & $\begin{array}{c}15 \\
15 \\
50 \\
15 \\
6\end{array}$ & $\begin{array}{c}25 \\
21 \\
37 \\
16 \\
2\end{array}$ & $\begin{array}{c}8 \\
35 \\
40 \\
15 \\
2\end{array}$ & $\begin{array}{c}23 \\
29 \\
30 \\
16 \\
2\end{array}$ & $\begin{array}{c}12 \\
22 \\
48 \\
14 \\
4\end{array}$ & $\begin{array}{c}16 \\
24 \\
41 \\
15 \\
3\end{array}$ \\
\hline $\begin{array}{l}\text { Percent who knew about DMPA } \\
\text { before the EngenderHealth } \\
\text { session } \\
\text { Yes } \\
\text { Yes, but not in detail } \\
\text { No }\end{array}$ & $\begin{array}{c}44 \\
47 \\
9\end{array}$ & $\begin{array}{l}55 \\
18 \\
27\end{array}$ & $\begin{array}{l}48 \\
33 \\
19\end{array}$ & $\begin{array}{l}40 \\
22 \\
38\end{array}$ & $\begin{array}{c}57 \\
36 \\
7\end{array}$ & $\begin{array}{l}50 \\
30 \\
20\end{array}$ \\
\hline $\begin{array}{l}\text { Number of private practitioners } \\
\text { attended EngenderHealth } \\
\text { information session }\end{array}$ & 34 & 56 & 48 & 55 & 83 & 138 \\
\hline $\begin{array}{l}\text { Percent who reported that the } \\
\text { information session added to their } \\
\text { existing knowledge about DMPA }\end{array}$ & 74 & 93 & 90 & 100 & 80 & 86 \\
\hline
\end{tabular}

* Percentage adds to more than 100 due to multiple responses 
The three most frequently cited reasons for participating in the seminars and study were: 1) a belief that DMPA is a good contraceptive method $(21 \%) ; 2)$ to gain more knowledge about the national family planning program (19\%); and 3) peer pressure to attend due to the seniority of the trainers $(16 \%)$. The last reason was reported by a large proportion of younger physicians from Ahmedabad: 38 percent of the physicians from Ahmedabad reported this as a reason for attending, compared to only about eight percent of the physicians from Baroda and Surat. The older physicians from Baroda and Surat were more likely to cite appreciation of learning new technical information on injectable contraceptive methods as the third most important reason for attending.

The majority of the physicians (63\%) reported that the EngenderHealth seminars were "very useful," principally because of the contraceptive technology update information that was presented by the trainers ( $52 \%$ of all physicians cited "latest knowledge" as the principal reason for finding the seminar useful). Approximately one-third of the MBBS physicians (38\%) did not know about DMPA before attending the seminars and a similar proportion of the OB/GYN physicians (36\%) indicated that their knowledge about DMPA was incomplete before the study. It is interesting to note that although the majority of the physicians reported the seminar as being either very useful or useful, a majority (approximately 56\%) disagreed with the statement "participating in programs like the EngenderHealth seminars enhances professional growth." The phrase "enhancing professional growth" was possibly a source of misunderstanding among some of the survey's respondents as other findings show that almost all of the physicians $(87 \%)$ reported that their technical knowledge of DMPA was improved as a result of the seminar.

Other findings clearly indicate the perceived benefit and usefulness of the EngenderHealth seminars for physicians' clinical practices (Figure 2). Approximately twothirds of the 139 physicians $(65 \%)$ reported that their clinical practice changed as a result of taking part in the study, and an almost equal proportion (70\%) of those who self-reported a change indicated that they are more likely to counsel patients and provide DMPA as a consequence of the EngenderHealth and DKT

Figure 2: Reported changes in medical practices

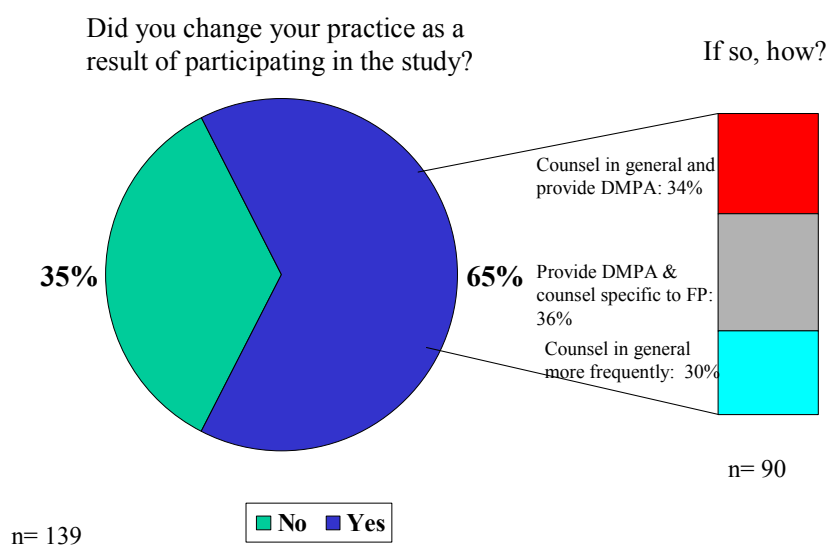
program.

\section{Provision of Injectable Contraceptives (NetEn and DMPA)}

Prior to the operations research study, DKT was supplying NetEn (two-month injectable contraceptive) to physicians in Gujarat as part of its social marketing program. Although DMPA was available through commercial outlets, the method was relatively unknown and substantially more costly than the two-month injectable. 


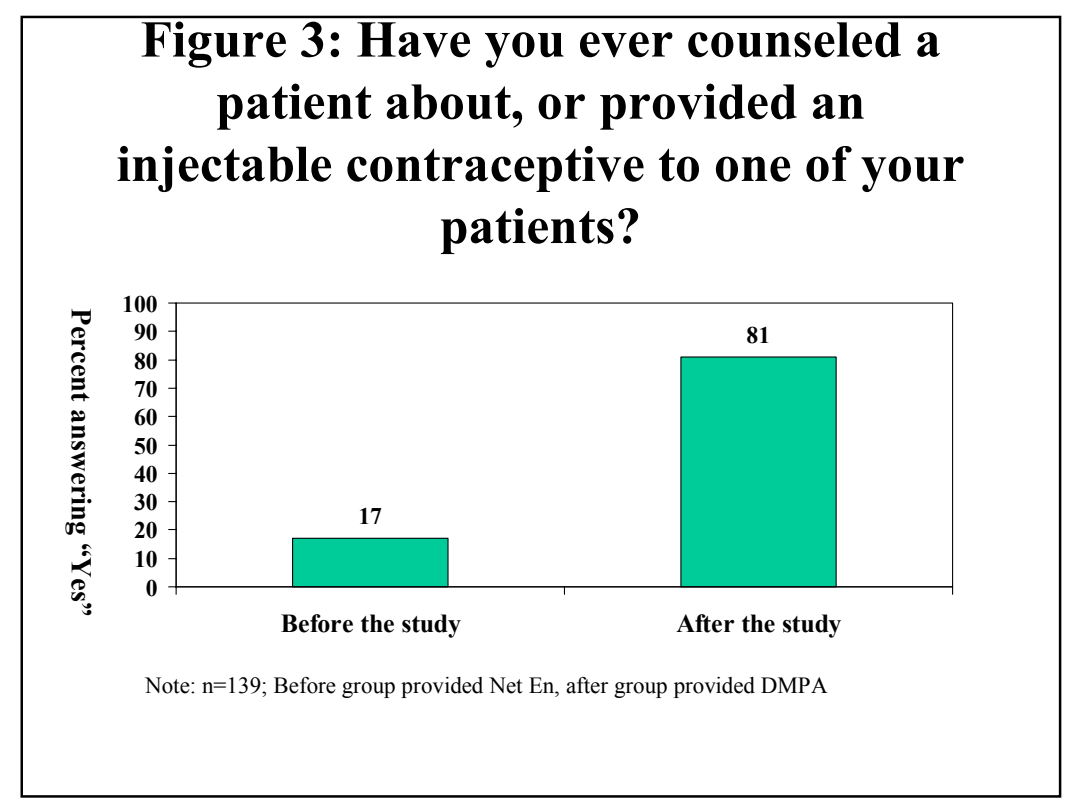

Approximately one-fifth $(17 \%)$ of physicians reported that they had prescribed or otherwise provided NetEn to one or more of their patients before the study (Figure 3).

These physicians were more likely to be $\mathrm{OB} / \mathrm{GYN}$ specialists $(26 \%$ of this group reported providing NetEn to patients before the study) than MBBS (only $4 \%$ of this group reported having previously provided NetEn). After taking part in the study, the large majority $(81 \%)$ of physicians interviewed

reported having provided, prescribed or counselled one or more patients about DMPA. MBBS and OB/GYN specialists were almost equally likely to do so: 71 percent of the MBBS and 88 percent of the $\mathrm{OB} / \mathrm{GYN}$ specialists indicated that they provided one or more type of DMPA service (not shown).

Table 6: Number of DMPA clients reported by physicians (percentage)

\begin{tabular}{|c|c|c|c|c|c|c|}
\hline & \multicolumn{3}{|c|}{ Location } & \multicolumn{2}{|c|}{ Specialty } & \multirow{2}{*}{$\begin{array}{l}\text { Total } \\
(\mathrm{n}=139)\end{array}$} \\
\hline & $\begin{array}{c}\text { Ahmedabad } \\
(\mathrm{n}=34)\end{array}$ & $\begin{array}{c}\text { Baroda } \\
(\mathrm{n}=57)\end{array}$ & $\begin{array}{c}\text { Surat } \\
(n=48)\end{array}$ & $\begin{array}{l}\text { MBBS } \\
(n=56)\end{array}$ & $\begin{array}{c}\text { OB/GYN } \\
(n=83)\end{array}$ & \\
\hline $\begin{array}{l}\text { Approximate number of } \\
\text { patients currently using } \\
\text { DMPA }\end{array}$ & & & & & & \\
\hline $1-2$ & 16 & 18 & 29 & 38 & 12 & 21 \\
\hline $3-5$ & 16 & 43 & 29 & 43 & 25 & 31 \\
\hline $6-10$ & 19 & 11 & 21 & 7 & 22 & 17 \\
\hline $11-20$ & 16 & 14 & 16 & 7 & 19 & 15 \\
\hline $21-50$ & 29 & 14 & 5 & 5 & 20 & 15 \\
\hline 51 and more & 3 & - & - & - & 1 & 1 \\
\hline Mean & 17 & 8 & 8 & 5 & 13 & 10 \\
\hline Range (Min-Max) & $1-60$ & $1-30$ & $1-50$ & $1-30$ & $1-60$ & $1-60$ \\
\hline
\end{tabular}

The average number of patients that physicians reported as currently using DMPA injectable was approximately 10 (Table 6). However, about one-third of the physicians (30\%) reported having between 11 and 50 current DMPA users among their patients. There is a substantial difference in the mean number of DMPA users by type of provider: MBBS physicians reported a mean of only 5.3 DMPA users while OB/GYN specialists reported a mean number of 13.3 DMPA users. The physicians in Ahmedabad reported a higher mean number of DMPA users (16.7) than physicians in Baroda (8.1) and Surat (8.2). 


\section{Knowledge of DMPA Injectable Contraceptive}

The findings from the survey of physicians' technical knowledge cannot be attributed to the EngenderHealth professional seminar/training program because the study did not obtain a baseline indicator of the participating physicians' knowledge. However, findings on the level of their knowledge are indicative of the capacity to provide quality services to women who seek out DMPA from these private practice physicians. In addition, even though no causal linkage can be established between the EngenderHealth training and the physicians' knowledge, a plausible case can be made that the intervention would have contributed to technical knowledge and improved clinical practice (as suggested by the previous findings on physicians' reported changes in clinical practice as a result of taking part in the study).

Table 7: Physicians' knowledge about timing and mechanism of action (percentage)

\begin{tabular}{|c|c|c|c|c|c|c|}
\hline & \multicolumn{3}{|c|}{ Location } & \multicolumn{2}{|c|}{ Specialty } & \multirow{2}{*}{$\begin{array}{r}\text { Total } \\
(\mathbf{n}=139)\end{array}$} \\
\hline & $\begin{array}{c}\text { Ahmedabad } \\
(\mathrm{n}=34)\end{array}$ & $\begin{array}{c}\text { Baroda } \\
(\mathrm{n}=57)\end{array}$ & $\begin{array}{l}\text { Surat } \\
(\mathrm{n}=48)\end{array}$ & $\begin{array}{l}\text { MBBS } \\
(n=56)\end{array}$ & $\begin{array}{c}\text { OB/GYN } \\
(n=83)\end{array}$ & \\
\hline \multicolumn{7}{|l|}{ Time when a client should start on } \\
\hline $\begin{array}{l}\text { Between first and seventh day of } \\
\text { menstruation }\end{array}$ & 85 & 79 & 69 & 70 & 82 & 77 \\
\hline $\begin{array}{l}\text { Anytime after seven days of } \\
\text { menstruation with backup contraceptive }\end{array}$ & 23 & 16 & 23 & 23 & 18 & 20 \\
\hline Six weeks postpartum for breastfeeding & 35 & 16 & 42 & 21 & 35 & 30 \\
\hline mother & 35 & 19 & 35 & 14 & 39 & 29 \\
\hline Immediately after MR/abortion & & & & & & \\
\hline Confirm no sign and symptoms of & 3 & 7 & - & 5 & 2 & 4 \\
\hline pregnancy & 6 & 2 & 2 & 2 & 4 & 3 \\
\hline $\begin{array}{l}\text { Do not know } \\
\text { Others }\end{array}$ & - & - & 4 & 2 & 1 & 1 \\
\hline \multicolumn{7}{|l|}{ Number of correct responses } \\
\hline 1 & 50 & 75 & 54 & 73 & 54 & 62 \\
\hline 2 & 15 & 12 & 21 & 16 & 16 & 16 \\
\hline 3 or more & 32 & 10 & 23 & 9 & 28 & 20 \\
\hline \multicolumn{7}{|l|}{$\begin{array}{l}\text { Knowledge about the mechanism of } \\
\text { action of DMPA }\end{array}$} \\
\hline $\begin{array}{l}\text { Suppress ovulation/reduce production of } \\
\text { hormones necessary for ovulation }\end{array}$ & 82 & 81 & 85 & 82 & 83 & 83 \\
\hline $\begin{array}{l}\text { Causes thickening of cervical mucus } \\
\text { acting as a barrier to sperm }\end{array}$ & 56 & 37 & 42 & 30 & 52 & 43 \\
\hline $\begin{array}{l}\text { Makes endometrium thin reducing chance } \\
\text { of implanting fertilized egg }\end{array}$ & 32 & 33 & 23 & 20 & 36 & 30 \\
\hline Do not know & 3 & 7 & 4 & 5 & 5 & 5 \\
\hline Long acting progesterone & - & - & 2 & 2 & - & 1 \\
\hline \multicolumn{7}{|l|}{ Number of correct responses } \\
\hline 1 & 44 & 60 & 56 & 68 & 46 & 55 \\
\hline 2 & 38 & 21 & 35 & 25 & 34 & 30 \\
\hline 3 or more & 18 & 19 & 8 & 7 & 20 & 15 \\
\hline
\end{tabular}

The majority of physicians (77\%) reported that a woman should start using DMPA between the first and seventh day of menstruation (Table 7). About two-thirds of the physicians in the study $(62 \%)$ gave only a single correct answer as to the time a woman can begin using DMPA (e.g., some physicians were unclear about when a woman should begin if she were breastfeeding, had had an abortion, or was not between the first and seventh day of menstruation). The large majority of the physicians in the study knew the principal mechanisms of action that DMPA exerts to avoid pregnancy: 83 percent reported it suppresses ovulation and 43 percent reported it causes a thickening of cervical mucus. In addition, about one-third of the physicians (30\%) indicated that it inhibits implantation 
through an effect on the endometrium. About 80 percent of the physicians knew one or two mechanisms of action. There were not large differences in the level of knowledge between MBBS physicians and OB/GYN specialists, although the specialists were more likely to report three or more correct responses on the timing and mechanisms of action. There are no substantial differences in the level of physicians' knowledge by the location of their practice (Ahmedabad, Baroda or Surat).

Table 8: Physicians' knowledge about the advantages of DMPA (percentage)

\begin{tabular}{|c|c|c|c|c|c|c|}
\hline & \multicolumn{3}{|c|}{ Location } & \multicolumn{2}{|c|}{ Specialty } & \multirow{2}{*}{$\begin{array}{c}\text { Total } \\
(\mathrm{n}=\mathbf{1 3 9})\end{array}$} \\
\hline & $\begin{array}{c}\text { Ahmedabad } \\
(\mathrm{n}=34)\end{array}$ & $\begin{array}{c}\text { Baroda } \\
(\mathrm{n}=57)\end{array}$ & $\begin{array}{l}\text { Surat } \\
(n=48)\end{array}$ & $\begin{array}{l}\text { MBBS } \\
(n=56)\end{array}$ & $\begin{array}{c}\text { OB/GYN } \\
(\mathbf{n}=\mathbf{8 3})\end{array}$ & \\
\hline Major advantages of DMPA * & & & & & & \\
\hline Requires no daily routine & 76 & 63 & 75 & 66 & 73 & 70 \\
\hline Long acting & 65 & 42 & 69 & 48 & 63 & 57 \\
\hline Can be safely used by women & 47 & 58 & 54 & 59 & 51 & 54 \\
\hline Easy to use & 56 & 51 & 50 & 48 & 54 & 52 \\
\hline Reversible method & 62 & 30 & 48 & 27 & 55 & 44 \\
\hline Can be used confidentially & 44 & 32 & 42 & 32 & 42 & 38 \\
\hline No effect on lactation & 47 & 26 & 42 & 21 & 47 & 37 \\
\hline Requires no action in sexual intercourse & 50 & 23 & 42 & 20 & 47 & 36 \\
\hline Most effective contraceptive & 38 & 28 & 25 & 30 & 29 & 29 \\
\hline Provides health benefits & 38 & 16 & 23 & 11 & 32 & 24 \\
\hline No advantage & 9 & 3 & 2 & 4 & 5 & 4 \\
\hline Others (correct responses) & 6 & 3 & 2 & 4 & 4 & 4 \\
\hline Do not know & - & 2 & - & 2 & - & 1 \\
\hline \multicolumn{7}{|l|}{$\begin{array}{l}\text { Number of advantages of DMPA } \\
\text { correctly mentioned }\end{array}$} \\
\hline 0 & 9 & 5 & 2 & 5 & 5 & 5 \\
\hline $1-2$ & 21 & 42 & 29 & 39 & 28 & 32 \\
\hline $3-5$ & 12 & 28 & 29 & 32 & 19 & 24 \\
\hline $6-7$ & 32 & 10 & 21 & 12 & 24 & 19 \\
\hline $8-10$ & 26 & 14 & 19 & 11 & 24 & 19 \\
\hline \multicolumn{6}{|l|}{$\begin{array}{l}\text { Non-contraceptive health benefits of } \\
\text { DMPA* }\end{array}$} & \\
\hline Reduced risk of vaginal yeast infection & 76 & 65 & 63 & 55 & 75 & 67 \\
\hline Reduced risk of endometrial cancer & 53 & 32 & 56 & 27 & 58 & 45 \\
\hline Reduced risk of acute PID & 38 & 32 & 31 & 21 & 41 & 33 \\
\hline Reduced symptoms of endometriosis & 53 & 25 & 29 & 9 & 49 & 33 \\
\hline Reduced risk of ectopic pregnancy & 32 & 26 & 29 & 18 & 36 & 29 \\
\hline Less bleeding, reduced anaemia & 18 & 2 & 10 & 7 & 10 & 9 \\
\hline $\begin{array}{l}\text { Reduced frequency and severity of sickle } \\
\text { cell disease crisis }\end{array}$ & 6 & 10 & 4 & 5 & 8 & 7 \\
\hline No non-contraceptive health benefit & 9 & 10 & 6 & 12 & 6 & 9 \\
\hline Others (correct responses) & 18 & 21 & 6 & 20 & 12 & 15 \\
\hline Do not know & - & 30 & 15 & 29 & 10 & 17 \\
\hline \multicolumn{7}{|l|}{$\begin{array}{l}\text { Number of non-contraceptive health } \\
\text { benefits of DMPA correctly mentioned }\end{array}$} \\
\hline 0 & 9 & 26 & 19 & 30 & 12 & 19 \\
\hline $1-2$ & 35 & 39 & 40 & 48 & 31 & 38 \\
\hline $3-4$ & 44 & 23 & 31 & 21 & 37 & 31 \\
\hline $5-6$ & 12 & 12 & 10 & - & 19 & 11 \\
\hline
\end{tabular}

* Percentage adds to more than 100 due to multiple responses

The majority of the physicians (approximately 57\%) reported between one and five major advantages of DMPA, and approximately one out of six physicians knew eight to 10 advantages (Table 8). The most commonly cited advantage of the three month injectable is that it requires no daily routine, followed by its long-acting properties, safety and ease of use. A little over two-thirds of the physicians $(69 \%)$ reported between one and four noncontraceptive benefits of DMPA, most commonly citing reduced risk of vaginal yeast 
infection and endometrial cancer. Although both MBBS and OB/GYN specialists had strong levels of knowledge about the advantages and non-contraceptive benefits of DMPA, the $\mathrm{OB} / \mathrm{GYN}$ specialists were more likely to cite more advantages and benefits than the generalists. The physicians from Ahmedabad (who are more likely to be younger than physicians from Baroda or Surat) cited more advantages and benefits than physicians from the other study sites. Over one-half of the physicians from Ahmedabad cited between six and 10 advantages (approximately 59\%), compared to only 24 percent and 39 percent of the physicians from Baroda and Surat. The results in Table 9 illustrate comparable differences in the proportion of physicians citing multiple non-contraceptive benefits across the three study sites as well.

Table 9: Physicians' knowledge of the disadvantages and side effects of DMPA (percentage)

\begin{tabular}{|c|c|c|c|c|c|c|}
\hline & \multicolumn{3}{|c|}{ Location } & \multicolumn{2}{|c|}{ Specialty } & \multirow{2}{*}{$\begin{array}{c}\text { Total } \\
(n=139)\end{array}$} \\
\hline & $\begin{array}{c}\text { Ahmedabad } \\
(\mathrm{n}=34)\end{array}$ & $\begin{array}{c}\text { Baroda } \\
(n=57)\end{array}$ & $\begin{array}{c}\text { Surat } \\
(\mathrm{n}=48)\end{array}$ & $\begin{array}{l}\text { MBBS } \\
(n=56)\end{array}$ & $\begin{array}{c}\text { OB/GYN } \\
(\mathrm{n}=\mathbf{8 3})\end{array}$ & \\
\hline Disadvantages of DMPA & & & & & & \\
\hline Prolonged or irregular bleeding & 79 & 61 & 54 & 54 & 70 & 63 \\
\hline Amaenorrhea & 65 & 60 & 58 & 43 & 72 & 60 \\
\hline Menstrual changes & 76 & 53 & 46 & 39 & 68 & 56 \\
\hline No protection against STIs/HIV & 50 & 26 & 44 & 23 & 48 & 38 \\
\hline Action cannot be stopped immediately & 47 & 25 & 29 & 21 & 39 & 32 \\
\hline Takes longer for fertility to return & 35 & 12 & 29 & 20 & 26 & 24 \\
\hline Weight gain & 3 & 7 & 4 & 11 & 1 & 5 \\
\hline No disadvantages/refusal to answer & - & 2 & - & 2 & - & 1 \\
\hline Others & 3 & 5 & - & 5 & 1 & 3 \\
\hline Do not know & - & 2 & - & 2 & - & 1 \\
\hline \multicolumn{7}{|l|}{ Number of correct responses } \\
\hline 0 & 3 & 9 & 4 & 12 & 1 & 6 \\
\hline $1-2$ & 26 & 47 & 56 & 59 & 36 & 45 \\
\hline $3-4$ & 35 & 32 & 23 & 25 & 32 & 29 \\
\hline $5-6$ & 35 & 12 & 17 & 4 & 30 & 19 \\
\hline \multicolumn{7}{|l|}{ Side effects of DMPA } \\
\hline Amenorrhoea & 59 & 46 & 46 & 29 & 63 & 49 \\
\hline Weight gain & 50 & 28 & 33 & 34 & 36 & 35 \\
\hline Prolonged/heavy bleeding & 44 & 37 & 23 & 34 & 34 & 34 \\
\hline Headaches & 29 & 17 & 23 & 20 & 24 & 22 \\
\hline Nausea & 18 & 14 & 27 & 23 & 17 & 19 \\
\hline Dizziness & 9 & 5 & 8 & 5 & 8 & 7 \\
\hline Others (correct responses) & 6 & 10 & 10 & 9 & 10 & 9 \\
\hline No problems & - & 2 & 4 & 4 & 1 & 2 \\
\hline Do not know & - & 7 & - & 5 & 1 & 3 \\
\hline \multicolumn{7}{|l|}{ Number of correct responses } \\
\hline 0 & 3 & 14 & 15 & 20 & 6 & 11 \\
\hline $1-2$ & 62 & 70 & 69 & 62 & 71 & 68 \\
\hline $3-5$ & 35 & 16 & 17 & 18 & 23 & 21 \\
\hline \multicolumn{7}{|l|}{$\begin{array}{l}\text { Menstrual changes resulting due to } \\
\text { use of DMPA }\end{array}$} \\
\hline Irregular bleeding & 76 & 60 & 62 & 46 & 77 & 65 \\
\hline Amenorrhoea & 65 & 63 & 62 & 55 & 69 & 63 \\
\hline Spotting & 44 & 47 & 48 & 37 & 53 & 47 \\
\hline Prolonged or heavy bleeding & 35 & 25 & 21 & 23 & 28 & 26 \\
\hline Others & - & 2 & - & 2 & - & 1 \\
\hline Do not know & - & 5 & 8 & 9 & 2 & 5 \\
\hline \multicolumn{7}{|l|}{ Number of correct responses } \\
\hline 0 & - & 7 & 6 & 9 & 2 & 5 \\
\hline $1-2$ & 56 & 65 & 73 & 82 & 54 & 65 \\
\hline $3-4$ & 44 & 28 & 21 & 9 & 43 & 29 \\
\hline
\end{tabular}


The results presented in Table 9 indicate that physicians' knowledge of the disadvantages and side effects of DMPA are commensurate with their knowledge of the benefits. Threequarters of the physicians in this study gave between one and four disadvantages of the threemonth injectable contraceptive method. The two most commonly cited disadvantages were prolonged or irregular bleeding (63\%) and amenorrhea (60\%). There were similar differences in the number of disadvantages cited by physicians in the three study sites as were noted in the distribution of responses about advantages: physicians in Ahmedabad were more likely to cite more disadvantages than were physicians in Baroda or Surat. A comparable pattern regarding potential side effects of DMPA use is shown in Table 10. The large majority (approximately 89\%) of physicians knew between one and five side effects, most commonly citing amenorrhoea (49\%) and weight gain (35\%). In response to a question asking for more detailed information on the type or nature of menstrual changes that may occur as a result of using DMPA, the physicians in this study exhibited a fairly strong level of technical knowledge: almost all of the physicians (95\%) reported at least one or two possible changes, most often citing irregular bleeding $(65 \%)$ or amenorrhoea $(63 \%)$.

Table 10: Physicians' knowledge of managing bleeding problems caused by DMPA (percentage)

\begin{tabular}{|c|c|c|c|c|c|c|}
\hline & \multicolumn{3}{|c|}{ Location } & \multicolumn{2}{|c|}{ Specialty } & \multirow{2}{*}{$\begin{array}{c}\text { Total } \\
(n=139)\end{array}$} \\
\hline & $\underset{(n=34)}{\text { Ahmedabad }}$ & $\begin{array}{c}\text { Baroda } \\
(n=57)\end{array}$ & $\begin{array}{c}\text { Surat } \\
(n=48)\end{array}$ & $\begin{array}{l}\text { MBBS } \\
(n=56)\end{array}$ & $\begin{array}{c}\text { OB/GYN } \\
(\mathbf{n}=\mathbf{8 3})\end{array}$ & \\
\hline Ways to manage* & & & & & & \\
\hline Through counseling before use & 65 & 54 & 65 & 50 & 67 & 60 \\
\hline Ongoing counseling during use & 41 & 33 & 44 & 30 & 45 & 39 \\
\hline Treatment using OCP, hormones & 47 & 23 & 25 & 21 & 35 & 29 \\
\hline Treatment using non-steroid & 35 & 9 & 17 & 5 & 26 & 18 \\
\hline $\begin{array}{l}\text { Stop use of DMPA and switch to } \\
\text { another contraceptive method }\end{array}$ & 26 & 30 & 31 & 25 & 33 & 29 \\
\hline Treatment using ibuprofen & 12 & 14 & 2 & 7 & 11 & 9 \\
\hline Next DMPA injection earlier & 3 & 12 & 2 & 5 & 7 & 6 \\
\hline Others & 12 & 18 & 4 & 21 & 5 & 12 \\
\hline Do not know & - & 3 & 6 & 7 & 1 & 4 \\
\hline Number of correct response & & & & & & \\
\hline 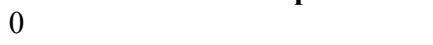 & - & 12 & 8 & 18 & 1 & 8 \\
\hline $1-2$ & 62 & 70 & 71 & 73 & 65 & 68 \\
\hline $3-4$ & 38 & 12 & 17 & 9 & 28 & 20 \\
\hline 5 or more & - & 5 & 4 & - & 6 & 4 \\
\hline
\end{tabular}

* Percentage adds to more than 100 due to multiple responses

Almost all of the physicians in the study (92\%) accurately reported one or more technique for managing bleeding problems caused by DMPA, and about one-quarter (24\%) reported three or more alternatives to assist women in managing this most commonly cited disadvantage of the method (Table 10). Providing counselling was the most frequently given management technique, both before beginning the method ( $60 \%$ of the physicians said this was important) and during initial use (39\% of the physicians indicated this was an important aspect of the clinical management of bleeding disorders). In other results (not shown) the reliance upon counselling by the physicians is also evident: approximately 73 percent reported that counselling the patient is an important technique for managing amenorrhoea. Approximately one-third of the physicians $(30 \%)$ indicated that oral contraceptives or another type of hormonal medicine might be used to manage bleeding, or that the woman could stop using DMPA and switch to another method if the bleeding was too much for her to manage successfully (Table 10). There were no substantial differences in the responses to this question by providers in the different study sites. However, important differences did emerge 
in the number of management techniques that MBBS physicians reported as compared to OB/GYN specialists: approximately one-fifth of the MBBS physicians (18\%) could not suggest a single technique for managing bleeding disorders, whereas only one OB/GYN physician (approximately 1\% of the sample) did not cite a management technique.

Table 11: Major contraindications to DMPA reported by physicians (percentage)

\begin{tabular}{|c|c|c|c|c|c|c|}
\hline & \multicolumn{3}{|c|}{ Location } & \multicolumn{2}{|c|}{ Specialty } & \multirow{2}{*}{$\begin{array}{c}\text { Total } \\
(n=139)\end{array}$} \\
\hline & $\begin{array}{c}\text { Ahmedabad } \\
(n=34)\end{array}$ & $\begin{array}{c}\text { Baroda } \\
(\mathrm{n}=57)\end{array}$ & $\begin{array}{c}\text { Surat } \\
(n=48)\end{array}$ & $\begin{array}{l}\text { MBBS } \\
(n=56)\end{array}$ & $\begin{array}{c}\text { OB/GYN } \\
(n=83)\end{array}$ & \\
\hline Major contraindications of DMPA* & & & & & & \\
\hline Hypertension/BP & 15 & 16 & 19 & 20 & 14 & 16 \\
\hline Breast cancer & 15 & 12 & 27 & 18 & 18 & 18 \\
\hline DUB & 12 & 7 & 6 & 9 & 7 & 8 \\
\hline Liver problem/hepatitis & 6 & 3 & 10 & 4 & 8 & 6 \\
\hline Diabetes & 21 & 9 & 12 & 12 & 13 & 13 \\
\hline Suspected pregnancy & 3 & 7 & 12 & 9 & 7 & 8 \\
\hline Dysmenorrhoea/menstrual pain & 3 & 12 & 15 & 18 & 6 & 11 \\
\hline Currently taking hormones for medical & & & & & & \\
\hline condition & 15 & 16 & 12 & 25 & 7 & 14 \\
\hline Newly married/nulliparous & 9 & 10 & 10 & 12 & 8 & 10 \\
\hline History of chronic illness/anemia & 18 & 12 & 6 & 7 & 14 & 11 \\
\hline Others & 20 & 14 & 8 & 11 & 16 & 14 \\
\hline No contraindication & 15 & 19 & 17 & 5 & 25 & 17 \\
\hline No response & 15 & 25 & 8 & 20 & 13 & 17 \\
\hline
\end{tabular}

* Percentage adds to more than 100 due to multiple responses

When physicians were asked to list what they considered to be major contraindications to DMPA, use the responses indicated a mixed level of understanding about the method specifically, and family planning in general (Table 11). Approximately one-fifth to one-sixth of the physicians in the study $(15-20 \%)$ gave medically correct responses (e.g., hypertension, breast cancer, diabetes or liver disease). Slightly more than one-sixth of the physicians (approximately 17\%) did not report any contraindications to DMPA use (which is different than not giving any response and is tantamount to saying "don't know" in the context of this question's wording). Interestingly, OB/GYN specialists were more likely to report that there are no contraindications to DMPA use than MBBS physicians (25\% versus $5 \%$ ). This finding suggests a shortcoming in the some physicians' knowledge about DMPA. The result that approximately 10 percent of the physicians in the study also reported that DMPA was contraindicated for newly married or nulliparous women suggests that a small but important proportion of physicians do not support the use of contraceptives for delaying the first birth. Other findings not shown in the tables reveal other shortcomings in the physicians' knowledge. For example, only 37 percent of the sample correctly reported that fertility normally returns within six months after discontinuing DMPA.

\section{DMPA Availability and Cost to Physicians}

Physicians who participated in this study had access to a DKT sponsored stockist who sold them DMPA ampules at a highly subsidized price (as described above). Each physician was visited on several occasions by DKT sales representatives and informed where the stockist was located. Stockists were conveniently located nearby all of the physicians in the study, and patients could be referred to the stockist for the purchase of the DMPA injection with a prescription, although fewer than one out of six physicians actually referred patients. Almost three-quarters $(70 \%)$ of the physicians in the study preferred to maintain a stock of the injectable contraceptive in their clinic for sale to their patients (Figure 4). Figure 4 also shows that about one-sixth of the physicians who agreed to take part in the study had not yet 
prescribed DMPA to a single patient in the eight months since the EngenderHealth seminar. Results (not shown) indicate that MBBS physicians were 50 percent less likely to have provided DMPA to a patient ( $21 \%$ versus $11 \%$ of OB/GYN specialists). These physicians were more likely to be in Baroda (21\%) than in Ahmedabad (9\%) or Surat (13\%).

\section{Figure 4: Provision of DMPA by location}

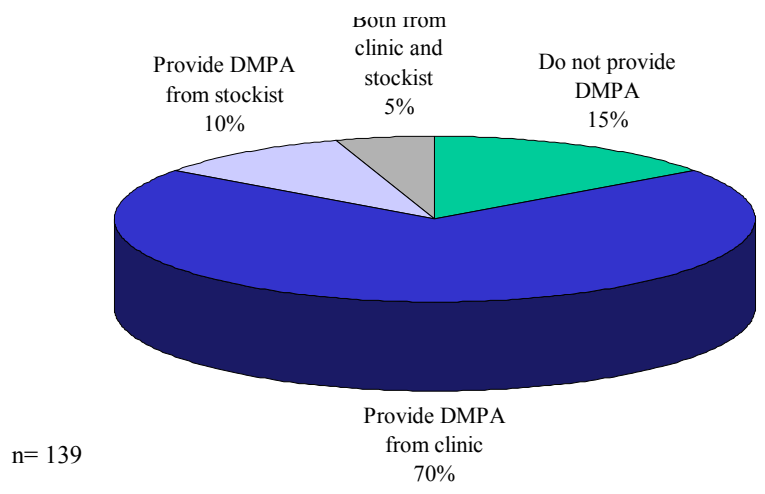

Figure 5: Price paid by physicians for a single DMPA ampule

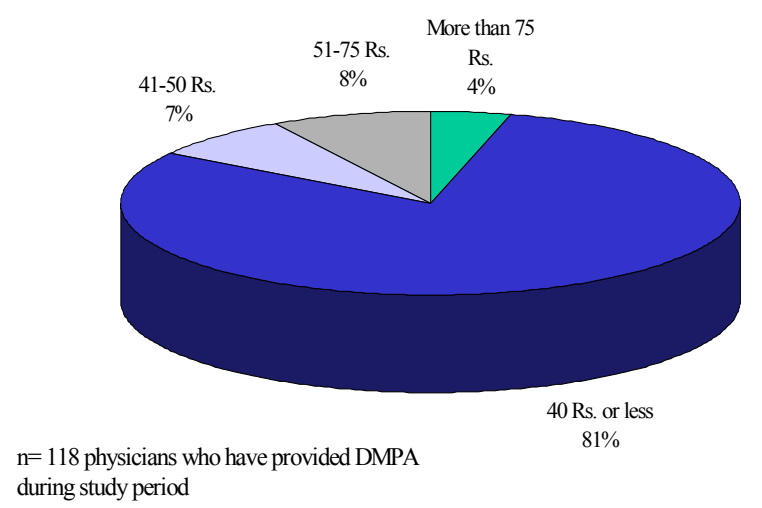

Under the terms of the study, DKT committed to provide DMPA ampules at a cost of Rs. 40 to participating physicians for the life of the study. (The regular subsidized price of Rs. 75 that DKT provides was further reduced in order to more closely match the worldwide rate for DMPA provided by many international donors.) The large majority of physicians $(81 \%)$ reported purchasing the DMPA injectable for Rs. 40 (Figure 5). The remaining physicians purchased ampules at a higher price, but did not report the source of the purchase. Results (not shown) indicate that the average maximum amount physicians believe women would be willing to pay for DMPA is Rs. 75, whereas the average affordable amount that physicians believe women could pay is about Rs. 72 . 


\section{DMPA Client Results}

A total of 352 first-time DMPA clients agreed to take part in the follow-up interview during the three-month enrollment period of April - June 2000. These clients formed the sample for this study. Table 12 presents the results of the interview process.

Table 12: Sample results of first-time DMPA clients

\begin{tabular}{|l|c|c|}
\hline \multicolumn{1}{|c|}{ Sample Results } & Percentage & Total (n) \\
\hline Completed interview & $52 \%$ & 184 \\
\hline Lost to follow-up: incorrect address & $36 \%$ & 88 \\
\hline Lost to follow-up: change of residence & $8 \%$ & 29 \\
\hline $\begin{array}{l}\text { Lost to follow-up: unavailable after three } \\
\text { contact attempts }\end{array}$ & $13 \%$ & 45 \\
\hline Refused interview & $2 \%$ & 6 \\
\hline $\begin{array}{l}\text { Total number enrolled during April - June } \\
2000\end{array}$ & $100 \%$ & 352 \\
\hline
\end{tabular}

The lost to follow-up rate for the subjects of this study is substantial. This is due, in part, to the fact that more than one-third of the sample's (36\%) address information was incorrect or incomplete. The external validity of the study (i.e., ability to generalize the findings to all first-time DMPA clients seen by private practice providers) is severely constrained because a large proportion (approximately 48\%) of the original sample failed to take part in the followup interviews. The reader is therefore cautioned against assuming broad-based representativeness and advised to consider the following results as informative of the experience a small group of first-time DMPA users seen by private practice physicians in three urban centres of Gujarat.

\section{Background Characteristics}

All of the women in the study were married and the large majority $(88 \%)$ reported that their husbands had not been away for a single night during the last six months. The average age of the sampled women was about 27 years; the youngest was 18 and the oldest was 50 (Table 13). Over one-quarter were over 30 years of age, and there is no substantial difference in the age of women between the three study sites. Relatively few women had not attended any school, almost one-half (approximately 42\%) reported they had completed either high school or higher secondary, and an additional 24 percent completed graduate or post-graduate school. They reported that their husbands' educational levels are comparable to their own, with about 41 percent of husbands having completed high school or higher secondary school and about one-third (31\%) having completed graduate or post-graduate education. Almost all of the women $(99.5 \%)$ reported that their husbands are employed, most commonly in a petty business $(36 \%)$ or service industry position $(42 \%)$. About 14 percent reported that they are also employed ("working for money") (not shown). A large majority (80\%) of the women in this study are Hindu, predominately from a higher caste (58\%). 
Table 13: Socio-demographic characteristics of the acceptors of DMPA (percentage)

\begin{tabular}{|c|c|c|c|c|}
\hline & \multicolumn{3}{|c|}{ Location } & \multirow{2}{*}{$\begin{array}{r}\text { Total } \\
(\mathrm{n}=184\end{array}$} \\
\hline & $\begin{array}{l}\text { Ahmedabad } \\
\quad(n=81)\end{array}$ & $\begin{array}{c}\text { Baroda } \\
(\mathrm{n}=57)\end{array}$ & $\begin{array}{c}\text { Surat } \\
(\mathrm{n}=46)\end{array}$ & \\
\hline \multicolumn{5}{|l|}{ Age of the acceptor } \\
\hline$<19$ years & - & 3 & 2 & 2 \\
\hline 20-24 years & 33 & 33 & 46 & 36 \\
\hline 25-29 years & 44 & 30 & 24 & 35 \\
\hline 30-34 years & 15 & 21 & 20 & 18 \\
\hline $35-39$ years & 7 & 5 & 6 & 7 \\
\hline 40 and more years & - & 7 & 2 & 3 \\
\hline Mean \pm SD & $27 \pm 4$ & $28 \pm 6$ & $27 \pm 6$ & $27 \pm 5$ \\
\hline Range & $20-39$ & $18-46$ & $19-50$ & $18-50$ \\
\hline \multicolumn{5}{|l|}{ Wife's Education completed } \\
\hline None & 2 & 12 & 6 & 6 \\
\hline Primary (classes 1-5) & 7 & 9 & 6 & 8 \\
\hline Middle (classes 6-8) & 10 & 10 & 17 & 12 \\
\hline High school/up to matric (classes 9-10) & 17 & 16 & 39 & 22 \\
\hline Higher secondary & 26 & 17 & 13 & 20 \\
\hline Intermediate & 6 & 3 & 6 & 5 \\
\hline Graduate & 22 & 17 & 2 & 16 \\
\hline Post-graduate & 5 & 12 & 9 & 8 \\
\hline Technical education & 4 & 2 & - & 2 \\
\hline \multicolumn{5}{|l|}{ Husband's Education completed } \\
\hline None & 2 & 5 & 2 & 3 \\
\hline Primary (classes 1-5) & 4 & 9 & 4 & 5 \\
\hline Middle (classes 6-8) & 2 & 10 & 11 & 7 \\
\hline High school/up to matric (classes 9-10) & 17 & 17 & 28 & 20 \\
\hline Higher secondary & 20 & 21 & 22 & 21 \\
\hline Intermediate & 11 & 2 & 2 & 6 \\
\hline Graduate & 27 & 21 & 20 & 23 \\
\hline Post-graduate & 7 & 9 & 6 & 8 \\
\hline Technical education & 9 & 5 & 4 & 6 \\
\hline \multicolumn{5}{|l|}{ Religion } \\
\hline Hindu & 79 & 79 & 85 & 80 \\
\hline Muslim & 15 & 19 & 13 & 16 \\
\hline Jain & 6 & 2 & 2 & 4 \\
\hline \multicolumn{5}{|l|}{ Caste } \\
\hline Scheduled caste & 2 & - & 9 & 3 \\
\hline Scheduled tribe & 1 & 2 & - & 1 \\
\hline Lower caste Hindu & 17 & 23 & 26 & 21 \\
\hline Higher caste Hindu & 58 & 58 & 59 & 58 \\
\hline Other religious groups & 21 & 17 & 6 & 16 \\
\hline \multicolumn{5}{|c|}{$\begin{array}{l}\text { Period when husband had been away from } \\
\text { home in the last six months }\end{array}$} \\
\hline None & 86 & 86 & 93 & 88 \\
\hline One month & 12 & 3 & 7 & 8 \\
\hline Two or three months & 2 & 11 & - & 4 \\
\hline
\end{tabular}


The findings presented in Figure 6 show that the firsttime DMPA users have a low parity, with the average number of living children being 1.6 (SD plus or minus 0.9). Almost one-half of the sample (47\%) were either nulliparous or had just one child, while 50 percent had two or three children and the remaining three percent had four or more. Almost 11 percent of women reported having lost a child (not shown). The average number of induced abortions among women in this sample is 1.4. Approximately 36 percent of the women interviewed reported having had at least one, and an additional 17 percent reported having at least one spontaneous miscarriage (not shown).

Approximately one-third (32\%) of first-time DMPA users in this study had their last pregnancy within the 12 months preceding the interview, and an additional one-third (35\%) had their last pregnancy between one and two years previous to the interview (Table 14). About three-quarters of the women reported that their last pregnancy ended in a live birth $(73 \%)$, while about one-sixth (16\%) indicated they had an induced abortion to terminate the pregnancy. Other findings (not shown) revealed that approximately 24 percent of women who had a pregnancy within the past year had a health problem that caused them to seek medical care from a physician. The results in Table 14 indicate that approximately one-

Table 14: Past pregnancy and future intentions (percentage)

\begin{tabular}{|l|c|}
\hline & TOTAL \\
\hline Timing of last pregnancy $(\mathbf{n}=\mathbf{1 8 4})$ & 3 \\
No pregnancy & 32 \\
<1 year & 35 \\
1-2 years & 12 \\
2-3 years & 7 \\
3-5 years & 11 \\
> 5 years & \\
\hline Outcome of last pregnancy $(\mathbf{n}=\mathbf{1 8 4})$ & 3 \\
No pregnancy/currently first time pregnant & 73 \\
Live birth & 1 \\
Still birth & 16 \\
Induced abortion & 7 \\
Spontaneous abortion/miscarriage & 27 \\
\hline Percent want to have more children $(\mathbf{n}=\mathbf{1 8 4})$ & \\
\hline Total number of children desired $(\mathbf{n}=\mathbf{5 0})$ & 84 \\
1 or more & 16 \\
Don't know & \\
\hline Time when they would like to have next child $(\mathbf{n}=\mathbf{5 0})$ & 18 \\
< 1 year & 46 \\
1-3 years & 28 \\
3-5 years & 4 \\
> 5 years & 4 \\
\hline Not in my hands/depends on others/can't say & \\
\hline
\end{tabular}

quarter $(27 \%)$ of the women who recently began using DMPA reported that they desired to have another child, most commonly just one more ( $84 \%$ of those who desired another). Among those who do want another child, 46 percent indicated that they want to wait one to three years before becoming pregnant, whereas about one-quarter $(28 \%)$ said they would wait three to five years. These findings suggest that while the majority of the DMPA users either do not desire any more children or are undecided about their reproductive intentions, a small but important number of firsttime DMPA users are using the method for spacing purposes. 


\section{Contraceptive Use Dynamics before Starting DMPA and Decision Making Influences on DMPA Use}

Slightly less than one-half of first-time DMPA users (41\%) reported that they had tried another contraceptive method since their last pregnancy before switching to DMPA (Figure 7). The methods most frequently used were the IUD (60\%) and oral contraceptives $(34 \%)$. This finding indicates that one-half of DMPA users may actually be switching from a longacting, inexpensive method (IUD) and bears further investigation. Approximately one-third of the DMPA clients reported having received a copy of the brochure on DMPA $(34 \%)$ or having seen one of the posters on DMPA (36\%) produced and distributed in the study. Apparently there was uneven distribution or use of the IEC materials by physicians in the three cities, as clients from Ahmedabad were more likely to report having received a brochure $(43 \%)$ than clients in Baroda $(37 \%)$ or Surat $(13 \%)$. However, clients from Baroda were more likely to have seen a poster on DMPA in their physician's office $(58 \%)$ than were clients from Ahmedabad (30\%) or Surat (20\%).

The results presented in Figure 8 clearly indicate the important role physicians assumed in assisting women in making the decision to begin using DMPA. Approximately three out of every four women reported that their first discussion on DMPA use was initiated by their physician. About one-sixth of the women in the study $(17 \%)$ said that they began the discussion about DMPA use. There was some variation in these findings across the three study sites: fewer women in Baroda indicated that the physician initiated discussion (68\%) about DMPA than women in Ahmedabad (82\%) or Surat $(83 \%)$. However, the majority of the study's respondents in each setting indicated that physicians began the discussion of DMPA use. Although these results indicate that physicians were proactive in describing DMPA to the women in their practices, other findings (not shown) reveal women's perceptions about this advice. When asked to rate the degree to which they thought the physician had encouraged

\section{Figure 7: Contraceptive use dynamics since the last pregnancy}



$\mathrm{n}=184 \quad \square$ No $\square$ Yes

\section{Figure 8: Who initiated the discussion about beginning DMPA use?}

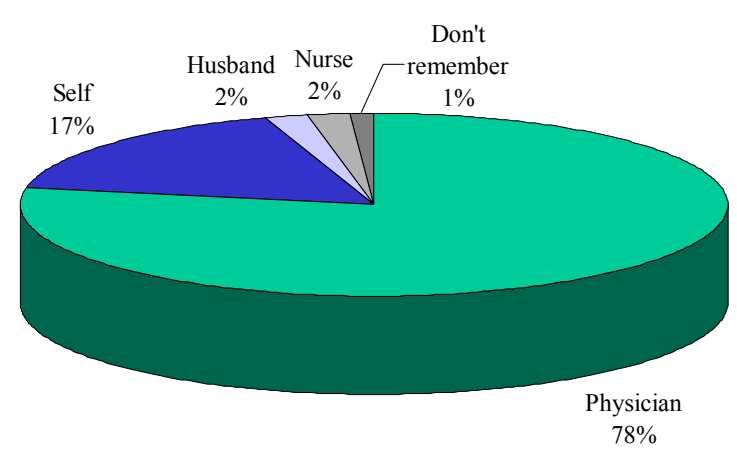

$\mathrm{n}=184$ 
DMPA use, only seven percent of the women said "very much," and over one-third (37\%) said the doctor had been neutral or even discouraging. Almost one-half (47\%) of first-time DMPA users reported that the physician had encouraged her "somewhat" (the remaining 9\% reportedly couldn't remember the level of encouragement they had received from the physician).

A minority of the women (30\%) who began using DMPA indicated that they would have preferred using another contraceptive method instead of DMPA (Figure 9). Among those women, the most frequently cited alternative method was the IUD $(57 \%)$, followed by oral contraceptives $(29 \%)$, and tubal ligation $(9 \%)$. In other findings (not shown),

Figure 9: Contraceptive method preference at time of first DMPA use

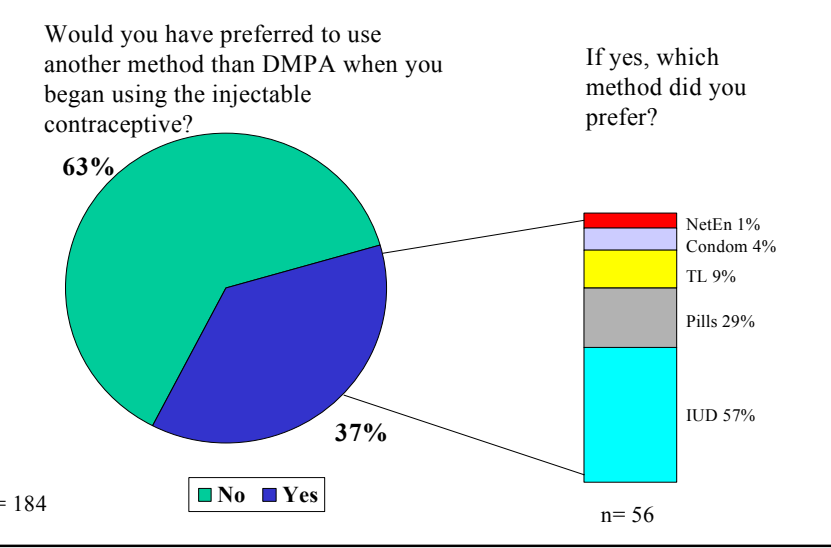

a pronounced difference in the preference of another method by study site emerges, as a much larger proportion of women in Ahmedabad indicated a desire to begin using the IUD $(77 \%)$ than women in Baroda (47\%) or Surat (41\%). Additionally not a single respondent in Ahmedabad reportedly desired a tubal ligation, whereas 18 percent of the DMPA users in Baroda and 12 percent of the DMPA users in Surat indicated that they would have preferred to have a sterilization procedure done instead of having an injectable contraceptive administered by the physician.

\section{Knowledge about DMPA}

Table 15: Information given at the time of first injection (percentage)

\begin{tabular}{|l|c|}
\hline & $\begin{array}{c}\text { TOTAL } \\
\text { (n=184) }\end{array}$ \\
\hline Told about the possibility of switching to another method & 24 \\
\hline Told about the possible side effects before beginning the use of DMPA & 51 \\
\hline Possible side effects of DMPA mentioned by physician (multiple responses) & 24 \\
Spotting & 22 \\
Heavy bleeding & 45 \\
Amenorrhoea & 12 \\
Backache & 17 \\
Otheight gain & 9 \\
\hline Informed about what to do if experience any of the possible side effects & 41 \\
\hline Told about problems that indicate one should come back to the clinic (apart from coming to the & 62 \\
clinic for the regular injections) & 85 \\
\hline Queries about DMPA were answered to complete satisfaction & 98 \\
\hline Know the correct interval (in months) between DMPA injections & \\
\hline
\end{tabular}


Only one-quarter (24\%) of first-time DMPA users said that they had been advised about the possibility of switching to another method before starting to use DMPA (Table 15).

However, about one-half of the women (51\%) who began using DMPA during this study reported that they were told about the possible side effects before receiving the first injection. The most frequently mentioned side effects discussed with the provider were amenorrhoea (45\%), spotting (24\%) and heavy bleeding (22\%). Slightly less than one-half (41\%) of the DMPA users said that they had been informed what to do if they experienced one or more of the side effects, but almost two-thirds (62\%) reported that they had been told of one or more particular conditions that indicate return to the physician for follow-up care.

These findings reflect two perspectives on clients' knowledge about how to manage side effects and indicate that around one-half of all clients know what to do if they experience a side effect from DMPA. Taken together with the finding that 51 percent of users reported being told about side effects, the overall impression is that a small majority of women who received DMPA from the physicians in this study received sufficient information on side effects. However, most of the first-time DMPA users said that all of their questions had been answered to their complete satisfaction (85\%). Almost all of the DMPA users (98\%) were able to correctly report the number of months that should elapse before receiving another injection.

\section{Experience with Side Effects}

Even though about one-half of the women who began using DMPA during this study received information about side effects, the large majority $(87 \%)$ reported experiencing one or more side effect sometime during the period of DMPA use (Figure 10).

Approximately one-quarter $(23 \%)$ of the DMPA users said that they experienced three or four side effects.

The side effect most frequently

\section{Figure 10: Number of side effects DMPA users experienced after one to three doses}



mentioned by DMPA users was spotting (40\%), followed by amenorrhoea (39\%), irregular menses, and prolonged or heavy bleeding (27\% each) (Table 16). The large majority of women who reported experiencing one or more side effect indicated that the condition was "very severe" as opposed to "somewhat severe." For example, almost all of the women who reported heavy bleeding (96\%) said the side effect was very severe. Only weight gain was more frequently indicated as being less than very severe (40\% "somewhat severe" as opposed to $37 \%$ "very severe"). The percentage of women reporting a side effect who sought help from a physician was about 70 percent, with as many as 90 percent of those who had prolonged or heavy bleeding saying that they sought medical help. 
Table 16: Nature of side effects experienced by DMPA users after one to three doses (percentage) (multiple responses possible)

\begin{tabular}{|l|c|c|c|c|}
\hline & \multirow{2}{*}{$\begin{array}{c}\text { Percent reporting } \\
\text { side effects } \\
\text { (n=184) }\end{array}$} & \multicolumn{2}{|c|}{$\begin{array}{c}\text { Severity of the side effects } \\
\text { experienced (n=184) }\end{array}$} & $\begin{array}{c}\text { Percent who sought } \\
\text { help from their } \\
\text { provider (n) }\end{array}$ \\
\cline { 3 - 5 } & & Very severe & $\begin{array}{c}\text { Somewhat } \\
\text { severe }\end{array}$ & \\
\hline Spotting & 40 & 61 & 30 & $72(74)$ \\
\hline Prolonged or heavy bleeding & 26 & 96 & 4 & $90(48)$ \\
\hline Amenorrhoea & 39 & 75 & 20 & $82(71)$ \\
\hline Irregular menses & 27 & 76 & 18 & $74(50)$ \\
\hline Weight gain & 19 & 37 & 40 & $43(35)$ \\
\hline Others & 18 & 47 & 50 & $59(34)$ \\
\hline
\end{tabular}

Approximately 55 percent of the women who sought help from a physician for a side effect received a check-up and some type of medicine, and an additional 23 percent reported they were told not to worry as the side effect was minor (results not shown). When asked to indicate which of the side effects they experienced was the most troublesome, women in this study were most likely to report amenorrhoea $(32 \%)$ or prolonged or heavy bleeding $(26 \%)$. The changes in menstrual patterns affected many of these women's abilities to perform religious activities.

\section{Continuation with the Second and Third Doses of DMPA}

Results that provide information on continuation rates among DMPA users are presented with a caveat about the small sample size and limited ability to draw firm conclusions or generalize the results to larger populations.

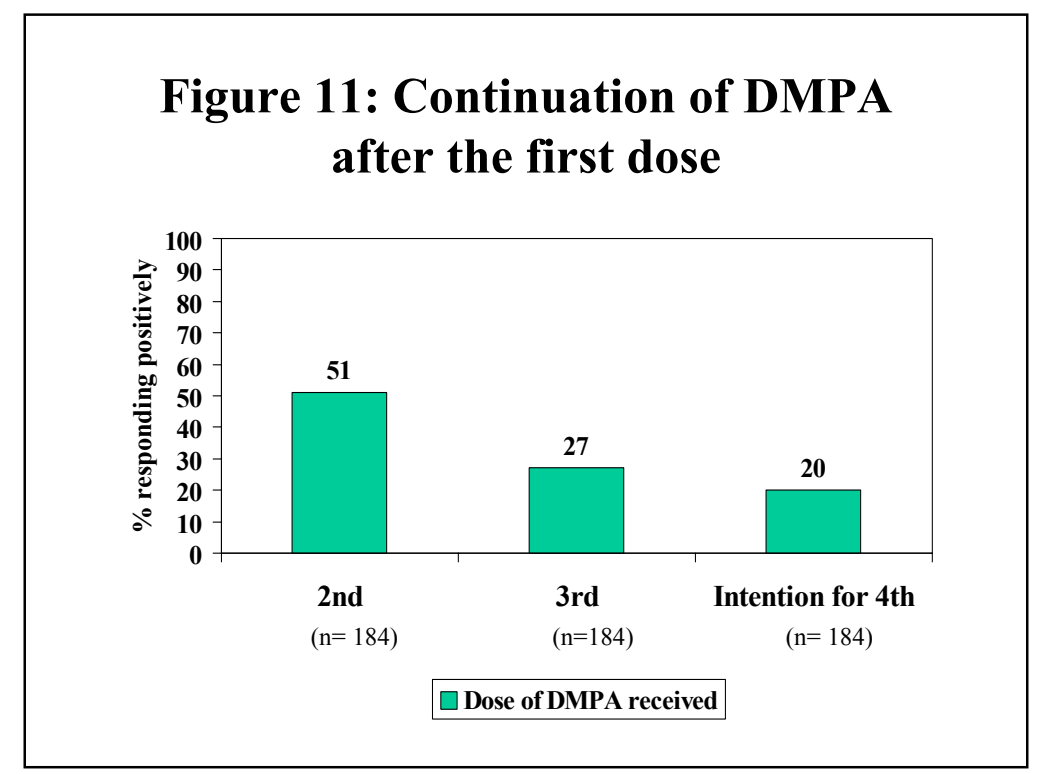

Among the 184 first-time users of DMPA who agreed to take part in this study, a little over one-half $(51 \%)$ received a second injection. Of those, about the same proportion $(54 \%)$ had a third injection (Figure 11). This means that between the first and second doses, and second and third doses, approximately one-half of all users decided to discontinue use of the method. By the time the women had reached the decision to take the fourth injection (i.e., at the time of the interview), about three-quarters of those who took a third dose $(74 \%, n=50)$ stated an intention to continue using DMPA. In total, 134 of the 184 first-time DMPA users $(73 \%)$ decided to discontinue use of the injectable contraceptive after one or two doses. The principal reasons given by women for discontinuing DMPA after the second or third dose 
was an inability to tolerate the side effects of menstrual disorders, $(75-80 \%$ of the reasons cited).

Table 17: Use of other contraceptive methods after stopping DMPA (percentage)

\begin{tabular}{|c|c|}
\hline & $\begin{array}{c}\text { TOTAL } \\
(n=74)\end{array}$ \\
\hline \multicolumn{2}{|l|}{ Method switched to after discontinuing DMPA } \\
\hline Vasectomy & 3 \\
\hline Tubectomy & 8 \\
\hline IUD & 15 \\
\hline Oral pills & 32 \\
\hline Condom & 26 \\
\hline Safe period & 13 \\
\hline Others & 3 \\
\hline \multicolumn{2}{|l|}{$\begin{array}{l}\text { Time when started using this method after discontinuing the DMPA } \\
\text { injection }\end{array}$} \\
\hline Within 15 days & 51 \\
\hline 15-30 days & 13 \\
\hline $1-2$ months & 13 \\
\hline 2-3 months & 8 \\
\hline 3-6 months & 13 \\
\hline \multicolumn{2}{|l|}{ Percent currently using } \\
\hline Same method switched to after the DMPA & 86 \\
\hline Method other than the one first tried to after the DMPA & 10 \\
\hline No FP method & 4 \\
\hline
\end{tabular}

Approximately one-half (55\%) of the women who stopped using DMPA switched to another contraceptive method such as oral pills (32\%), condoms $(26 \%)$, IUD $(15 \%)$, or a permanent method (tubal ligation $8 \%$ or vasectomy $3 \%$ ) (Table 17 ). The majority of women who switched to another method (51\%) did so within 15 days after discontinuing the injectable method. At the time of the interview, the large majority (85\%) of women who had stopped using DMPA but had begun using another method were still using the same contraceptive method begun after DMPA. An additional 10 percent were still using family planning but had switched again to another method. In total, 60 of the 184 first-time DMPA users in this study (33\%) stopped using contraceptive methods entirely after discontinuing use of the injectable after the first, second or third dose (not shown).

\section{Cost of DMPA as Reported by First-Time DMPA Users}

The results presented in Table 18 suggest that cost savings to physicians (who were provided ampules by DKT stockists at the subsidized price of Rs. 40) were not, in fact, passed on to clients. The average amount paid by the DMPA users for a single ampule was Rs. 103, excluding physician's consultation fees (Table 18). This amount is substantially more than the Rs. 84 that women in the study indicated as the maximum reasonable amount they would pay per ampule. It is almost twice as much as the Rs. 55 that these women reported as affordable for a single DMPA ampule. There is a large discrepancy between the amount paid by DMPA clients per ampule and the amount paid by physicians (Figure 5). Almost threequarters of the physicians indicated that they routinely pay on average Rs. 48. Apparently physicians are imposing a surcharge to their clients for the contraceptive. 
Table 18: Cost of DMPA (Rs.) reported by users (percentage)

\begin{tabular}{|l|c|}
\hline & $\begin{array}{c}\text { TOTAL } \\
\text { (n=184) }\end{array}$ \\
\hline Amount paid for the DMPA excluding consultation fees & \\
$\leq 50$ & 24 \\
$51-100$ & 36 \\
$101-200$ & 25 \\
$\geq 201$ & 5 \\
Do not know & 10 \\
Mean & $103 \pm 57$ \\
Range & $20-350$ \\
\hline Maximum amount that is reasonable to pay for a DMPA ampule, excluding doctors fees & \\
$\leq 50$ & 39 \\
$51-100$ & 36 \\
$\geq 101$ & 14 \\
Do not know & 11 \\
Mean & $84 \pm 59$ \\
Range & $10-500$ \\
\hline Affordable amount that is reasonable to pay for a DMPA ampule, excluding doctors fees & \\
$\leq 25$ & 24 \\
$26-50$ & 45 \\
$51-100$ & 15 \\
$\geq 101$ & 6 \\
Do not know & 9 \\
Mean & $55 \pm 56$ \\
Range & $10-500$ \\
\hline
\end{tabular}

\section{UTILIZATION}

The results from this study will be disseminated through a series of targeted briefings and specialized summaries for key decision makers in the Indian national family planning program. Attention will be given to reaching individuals and groups working in different sectors, including social marketing agencies, non-governmental organizations, donors, and the Ministry of Health and Family Welfare (central and state level authorities). FRONTIERS will collaborate with the USAID Mission in New Delhi, DKT India and EngenderHealth to conduct targeted briefings. In addition to these briefings and small group meetings, FRONTIERS will work through the Population Council network of informed journalists to insert key findings, or to commission topical articles in leading daily newspapers in Delhi and in the three cities targeted by the study. The dissemination of key findings within a context of informed choice and expanding contraceptive options to women will lead to sharing information with a wide audience.

The dissemination strategy will have multiple objectives. The study's findings will be used to contribute to on-going discussions within the MOFW about the addition of DMPA to the national family program, and to stimulate discussion within selected states about conducting a limited introduction program. Social marketing agencies working in India will be presented results from the study that demonstrate how DMPA can be successfully introduced into private practice medical settings. 


\section{CONCLUSIONS AND RECOMMENDATIONS}

\section{First-Time DMPA Users}

There are several limitations on the results from this study that constrain the internal and external validity of the client findings. The principal outcome indicator that drove the study design was assessment of discontinuation rates of first-time DMPA users who obtained the method in private clinical practices. Because the caseload of eligible DMPA clients was smaller than anticipated, the ability to calculate life table analysis was of borderline strength, even considering a very high response rate. The January 2001 earthquake restricted access to almost 60 percent of the sample of enrolled first-time users, obviating the ability to provide any information on continuation that could be considered representative of all DMPA users seeking care from the private practice physicians in this study, or for other groups of DMPA users of similar characteristics in India. A second limitation on the study's results is due to the high lost to follow-up rate $(48 \%)$. This was caused by the physicians' failure to note sufficient information on the client locator card at the time of enrollment in the study. The high non-response rate limits the ability to generalize results even to the sample of first-time patients who agreed to take part in the study. In conclusion, the study presents information on the experiences of the 184 first-time users who responded to the survey, and all conclusions must necessarily be drawn only about that group of women and no others.

After taking into consideration the two principal limitations on the client-related findings, the study is able to provide several very interesting insights into the experience these women had with the DMPA contraceptive method. Because of the study's limitations, it is important to consider the social and economic characteristics of the women who responded to the interviewer's questions. This group of first-time DMPA users were, on average, in their late 20 s, well-educated and low parity, with employed husbands. The majority of these women did not want any more children, but slightly less than one-half reported having used a contraceptive method since their last pregnancy. They came to know about DMPA during visits to their physicians. The IEC materials were effective in reaching women with information about DMPA - about one-third of the DMPA users reported seeing one or both of these materials. However, brochures and posters were unevenly distributed, which apparently limited women's exposure to their messages.

Three-quarters of the women in this study reported that the physician first brought to their attention the possibility of trying DMPA. The proactive role of physicians can be a cause of concern if the provider exerts undue influence or pressures the woman to accept the method. This was not the case among women in this study, perhaps because of their educational level or because of the private practice setting where the physicians operate. In any case, one out of three DMPA users reported that the physician was neutral in his remarks about trying DMPA, while an additional 47 percent indicated that the physician had only been "somewhat" encouraging. These findings indicate that physicians acted responsibly in their promotion of the DMPA method during the study, reaching as many of their patients as possible with information on DMPA but not exerting pressure on women to accept the method.

The information provided to women about DMPA before they began use was fairly complete, yet there was clearly room for improvement. For example, about one-quarter of the clients 
said they had been told about the possibility of switching to another method before beginning DMPA. This may have been due to the providers' perception that these women already knew about how to switch to another method (given their previous contraceptive use history and educational level) but nevertheless, this message is a standard element of counselling. More troubling is the finding that only about one-half of the first-time DMPA users reported being told about potential side effects and what to do if they experienced a side effect. A large majority of the first-time DMPA users did, in fact, experience side effects: 87 percent said they had one or more unwanted effects and 70 percent of those sought medical care as a consequence. The high incidence of side effects had a direct effect on the women's decisions to continue using DMPA.

Of the 184 first-time DMPA users contacted seven months after their first dose, only about one-quarter were still using the method. Not all of the women who had taken three doses of DMPA $(27 \%$ of the original 184$)$ indicated that they were going to take a fourth dose as well - only about one in five of the original users were expected to take the fourth injection. These results show that after an initial steep decline after two to three doses, the number of discontinuers probably levels off. These results are comparable to the 1998 DMPA study conducted by the Population Council in Uttar Pradesh where only 19 percent of the DMPA users continued to use the method at the time of the fourth dose. In addition, the continuation rate is comparable to data from the Philippines where an operations research study conducted by the Population Council showed that by the end of a 15-month period only 31 percent of the original cohort of DMPA users returned for a fifth injection. ${ }^{5}$ Clearly the DMPA method is not for all women, or even a majority, but after a period of trial use it is reasonable to expect that about 20-30 percent of users will continue with the method. In this context, the ability to switch to another method is critically important.

The majority (55\%) of women who tried DMPA but found the side effects intolerable switched to another contraceptive method. About one-third of the women who stopped DMPA were not using another method at the time of the interview. It is plausible that these women were simply waiting to resume normal menstrual cycles after stopping DMPA and would eventually begin using another method (given their previous contraceptive use histories, educational levels, and reproductive intentions).

Although none of the women in this study specifically stated that the cost of the DMPA injection was an element in their decision to stop using the method, the average amount that these women reported paying for the DMPA injection (Rs. 103) was substantially more than the mean cost that was indicated as affordable (Rs. 55), and the mean cost that was judged to be reasonable (Rs. 84). DKT India provided the injectable contraceptive to physicians in the study for Rs. 40. There is a large discrepancy between the amount that physicians paid for the DMPA ampule and the amount clients say they paid for the contraceptive. This difference could be due to providers adding a fee, or to clients reporting an inflated price; it is impossible to tell. However these results suggest a client willingness to pay between Rs. 55 and 84 .

\footnotetext{
5 "DMPA Monitoring Study: Findings on Use and Continuation Rates." Population Council ANE OR/TA Project Final Report. September 1995.
} 


\section{Health Care Providers}

The majority of the private sector physicians in this study were OB/GYN specialists and had been practicing medicine for some time - on average about 17 years. There is a notable incidence of physicians in the study donating some portion of their time to providing honorary medical services, in part reflecting the strong sense of community purpose that exists throughout Gujarat. These physicians work in busy settings with a high daily caseload. On average, the MBBS physicians reported seeing 48 patients per day and the OB/GYN physicians saw 25 patients per day. About two-thirds of these physicians work in solitary practice settings. Three-quarters of the OB/GYN physicians reported that they routinely provide family planning services as part of their medical practice, but less than one-tenth of the MBBS physicians provided family planning services before the study.

Although the physicians in this study were not available to take part in a two-day training program, they did seem to appreciate the abbreviated one-day professional seminar that EngenderHealth organized. About two-thirds of the physicians reported the daylong seminar as being "useful," and the large majority (87\%) reported that they learned something new about DMPA as a result of attending the meeting. An impressive two-thirds of physicians who were interviewed stated that they changed some element of their medical practice as a direct result of participating in the EngenderHealth seminar. These results, and other findings reported in the EngenderHealth final report, suggest that even though private practice physicians are not easily accessible for in-service training, immediate benefits do accrue from condensed, well-prepared training programs.

Before the study began, very few of the physicians had provided an injectable contraceptive (less than one-fifth reported having counselled a patient or prescribed NetEn). After taking part in the EngenderHealth seminar and gaining access to the DKT India supply of DMPA, fully 81 percent of the physicians counselled patients or prescribed DMPA. At the time of the interviews (about nine months after the EngenderHealth training), the physicians in the study reported an average of 10 current users of DMPA in their practices. Although the study was not able to confirm this number, the finding does suggest that after receiving even a brief training, and with a continuous supply of the DMPA method, private practice physicians will seek out appropriate patients to counsel and provide the injectable contraceptive method.

\section{Recommendations}

The ability to generate recommendations is limited by the special characteristics of the physicians who took part in the DKT India program in Gujarat, the high loss to follow-up rate among DMPA clients, and the small sample size. Therefore, the following points are offered as tentative recommendations for program managers to consider as they work towards expanding contraceptive choice for women in India:

- The DMPA injectable contraceptive should be offered through social marketing programs in India, in conjunction with professional support services such as IEC materials and professional development opportunities. OB/GYN specialists may be a more appropriate category of physicians for reaching women with family planning services in general. 
- The price of DMPA should be reduced from the current procurement price of Rs. 75 per ampule that NGOs pay the supplier to an amount that provides a maximum retail price for the client of between Rs. 40 and 55 .

- DMPA should be made available in multiple service delivery systems (e.g., other than social marketing or private sector settings) that can ensure provider technical competence and informed choice, including the provision of other temporary methods. 